\title{
Performance optimisation of room temperature magnetic refrigerator with layered/multi-material microchannel regenerators
}

\author{
Muhammad Sajid Kamran ${ }^{\mathrm{a}, \mathrm{b}^{*}}$, Hassan Ali ${ }^{\mathrm{a}}$, Muhammad Farhan ${ }^{\mathrm{a}}$, Yong Bai Tang ${ }^{\mathrm{c}}$, Yong Gui Chen ${ }^{\mathrm{c}}$, Hua \\ Sheng Wang ${ }^{\mathrm{b}}$ \\ ${ }^{a}$ Department of Mechanical Engineering, University of Engineering and Technology, Lahore, 54890, \\ Pakistan. \\ ${ }^{\mathrm{b}}$ School of Engineering and Materials Science, Queen Mary, University of London, Mile End Road, London \\ E1 4NS, UK \\ ${ }^{\mathrm{c}}$ School of Materials Science and Engineering, Sichuan University, Chengdu 610065, China
}

\begin{abstract}
A hybrid numerical model of the magnetic refrigerator with multi-material microchannel regenerator has been developed. The magnetocaloric effect was implemented using instantaneous temperature rise/drop (discrete method). Two pipe-in-pipe heat exchangers at two ends of the regenerator were treated using $\varepsilon-\mathrm{NTU}$ method. The commercially available compounds of $\mathrm{LaFe}_{13-\mathrm{x}-}$ ${ }_{\mathrm{y}} \mathrm{Co}_{\mathrm{x}} \mathrm{Si}_{\mathrm{y}}$ as well as hypothetical compounds of Gadolinium were considered as the magnetocaloric materials (MCMs) with different Curie temperatures. The predicted results of the present work for parallel regenerators employing different compounds of $\mathrm{LaFe}_{13-\mathrm{x}-\mathrm{y}} \mathrm{Co}_{\mathrm{x}} \mathrm{Si}_{\mathrm{y}}$ were broadly in good agreement with the available experimental data. The cooling capacity increases as the number of MCMs increase. However, for a given length of regenerator, an optimum number of MCMs was seen yielding the maximum performance of the refrigerator. For a given number of MCMs, a smaller Curie temperature difference $\Delta T_{\mathrm{Cu}}$ between the MCMs was found to give higher performance.
\end{abstract}

Key words: Magnetic refrigeration, Microchannel regenerator, Numerical modelling, Magnetocaloric material, Multi-material/Layered regenerator

\section{Highlights:}

- A multi-MCM microchannel regenerator is used for numerical simulation of magnetic refrigerators.

- $25 \%$ higher no-load temperature span was achieved with 3-MCMs compared to single MCM.

- Optimised Curie temperatures difference of two consecutive MCMs is found in a given range.

- Influence of hot end temperature on the cooling capacity is investigated.

\footnotetext{
*Corresponding author: Department of Mechanical Engineering, University of Engineering and Technology, Lahore, 54890, Pakistan.

Tel: +923311492222

Email address: m.s.kamran@uet.edu.pk
} 


\section{Introduction}

Magnetocaloric effect (MCE) is a phenomenon exhibited by certain rare earth metals such as $\mathrm{Gd}, \mathrm{Mn}, \mathrm{Yd}, \mathrm{La}$ and their alloys etc. in the form of temperature or entropy change upon their exposure to a changing magnetic field. The materials exhibiting MCE are known as the magnetocaloric materials (MCMs). The severity/magnitude of MCE is strongly reliant upon of the change in the magnetic field $(\Delta B)$ as well as the temperature of the MCM $[1,2]$. The peak MCE is observed when the temperature of the MCM is the same as Curie temperature of the MCM and its value drops as the temperature of the MCM differs from its Curie temperature. Figure 1 shows the dependence of MCE on the temperature of the MCM and change in magnetic field for different MCMs [3]. Gadolinium (Gd) has Curie temperature of $24^{\circ} \mathrm{C}$ and it shows the maximum temperature change per unit change in the magnetic field among the second order magnetic transition (SOMT) materials (up to $3.0 \mathrm{KT}^{-1}$ theoretical value and 1.5-2.0 $\mathrm{KT}^{-1}$ experimental [4]). It has thus become the most commonly employed MCM in magnetic refrigeration till date [5-7].

Magnetic refrigeration is a promising new technology with potential to provide an alternative for conventional refrigeration techniques. It employs the phenomenon of MCE to produce useful cooling/heating. There are three different cycles upon which a magnetic refrigerator can be operated (a) Magnetic Carnot Cycle; (b) Magnetic Ericsson Cycle and (c) Magnetic Brayton or Active Magnetic Regenerative Cycle. The Carnot cycle serves as a theoretical reference for the performance comparison of other operating cycles. The Ericsson cycle requires very large magnetic field change to produce significant cooling and temperature span. Electromagnets are normally used to produce magnetic fields larger than $1.5 \mathrm{~T}$ but their operation can be cumbersome and expensive when compared with a permanent magnet assembly [8]. A significant number of prototype magnetic refrigerators have been developed over the last two decades operating on active magnetic regenerative cycle [5-7]. Active magnetic regeneration is based on progressively building a temperature gradient along the length of the MCM regenerator. The cycle consists of four stages namely (i) magnetisation; (ii) flow from one end to other through the MCM; (iii) demagnetisation; (iv) flow from reverse end. As the number of regenerative cycles increase the temperature at one 
end is maintained at the ambient temperature while at the other end temperature continues to drop (to form the cold end) till a steady state longitudinal/axial temperature gradient is established. The difference of temperature at ends is temperature span of the magnetic refrigerator for a given cooling load. Single MCM, such as Gd based regenerators show limited temperature spans across two ends of the regenerator [6]. One of the factors restricting the temperature span is the gradual decline in MCE value since the local temperature of the MCM has commenced to deviate from its Curie temperature. During subsequent magnetisations/demagnetisations, the MCM regions possessing temperature closer to its Curie temperature experience relatively larger MCE whereas the regions with temperature farther from the Curie value undergo smaller MCE. This behaviour ultimately limits the maximum achievable temperature span across the regenerator. One common method of enlarging the regenerator temperature span is by the use of more than one MCM with different Curie temperatures along the length of regenerator [9-16] . MCM with the lowest $T_{\mathrm{Cu}}$ is laid at the cold end while the MCM with highest $T_{\mathrm{Cu}}$ at the hot end so that each MCM experiences maximum possible MCE. Arnold et al.[9] conducted experiments on two-MCM based regenerators under $2 \mathrm{~T}$ and $5 \mathrm{~T}$. No-load temperature spans of $33 \mathrm{~K}$ and $59 \mathrm{~K}$ were reported under $2 \mathrm{~T}$ and $5 \mathrm{~T}$, respectively. Tusek et al. [10] performed experimental investigations on four different compound of LaFeCoSi having tailored Curie temperatures. Similarly, Legait et al. [11] employed three different types of MCMs with tailored Curie temperatures in different regenerators and reported larger temperature span for the multi-MCM regenerator. Aprea et al.[12] employed three MCMs to examine the performance of a layered regenerator. However, the chosen MCMs were not possessing specifically tailored $\left(\mathrm{Gd}: T_{\mathrm{Cu}}=294 \mathrm{~K}\right.$; Dy: $\left.T_{\mathrm{Cu}}=179 \mathrm{~K} ; \mathrm{Tb}: T_{\mathrm{Cu}}=230 \mathrm{~K}\right)$ and thus resulted in insignificant improvement in the performance. Hsieh et al. [13], Monfared and Palm [14] and Lie et al. [15] numerically evaluated the performance of layered bed regenerator using $\mathrm{Gd}_{\mathrm{x}} \mathrm{Tb}_{1-\mathrm{x}}$. alloys and inferred that two and three MCM based regenerators yielded considerably better performance compared to single material regenerator. 
Importantly, recent research in magnetocaloric materials (Katter et al. [17], Katter et al. [18], Katter et al. [19], Bjork et al. [20], Barcza et al. [21], Bahl et al. [22], Radulov et al. [23] and Pulko et al.[24]) demonstrates the possibility of tailoring the Curie temperature of alloy MCMs to desired values (in the room temperature range) by changing the chemical composition of its constituting elements. Katter et al. [19] and Bjork et al. [20] have reported the tuning of magnetocaloric characteristics of $\mathrm{LaFe}_{13-\mathrm{x}-\mathrm{y}} \mathrm{Co}_{\mathrm{x}} \mathrm{Si}_{\mathrm{y}}$ compounds. The Curie temperatures of these compounds were altered by varying the percentage mass of their chemical constituents $\mathrm{La}, \mathrm{Fe}, \mathrm{Co}$ and $\mathrm{Si}$. Various compounds of $\mathrm{LaFe}_{13-\mathrm{x}-\mathrm{y}} \mathrm{Co}_{\mathrm{x}} \mathrm{Si}_{\mathrm{y}}$ have been prepared with different Curie temperatures and are available commercially (e.g. Vacuumschmelze $\mathrm{GmBH})$.

Experimental comparisons performed by Tusek et al. [10] and Legait et al. [11] between single and multi-MCM regenerator reveal improved performance of magnetic refrigerator while using multi-MCM regenerator. However, experimental investigations are constrained by number of possible multi-MCM settings that can be examined such as number of MCMs, Curie temperature of the MCMs and Curie temperature difference between two adjacent materials. In addition, due to unavailability of Gd based alloys, the majority of comparisons have been made for non-Gd MCMs and their respective alloys. So far single-MCM Gd regenerator has been reported to show larger temperature span compared to multi-MCM non-Gd regenerator [10, 11]. It can thus be expected that a multi-MCM regenerator with different Gd alloys would yield considerably better performance than the multi-MCM regenerator of non-Gd alloys such as $\mathrm{LaFe}_{13-\mathrm{x}-\mathrm{y}} \mathrm{Co}_{\mathrm{x}} \mathrm{Si}_{\mathrm{y}}$. The present work numerically evaluates the performance of a multi-MCM microchannel regenerator employing hypothetical compounds of Gd. The present numerical predictions can pave the way for future developments of Gd based alloys/compound and their applications in active magnetic regenerator.

\section{Single Column Figure}




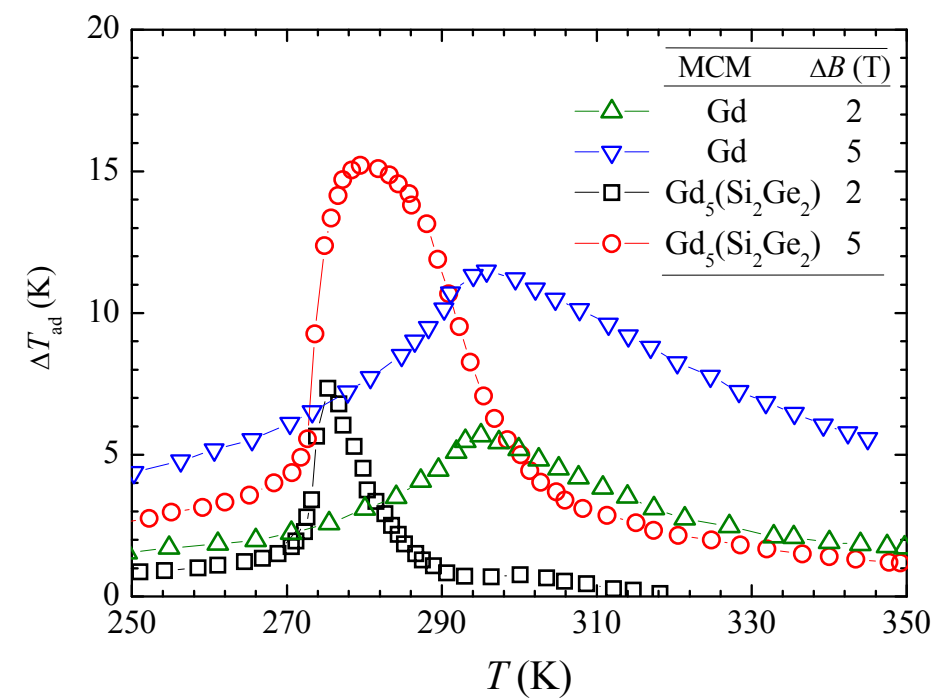

Figure 1 Variation of adiabatic temperature change $\Delta T_{\text {ad }}$ with temperature for different magnetic field variations (reproduced from Pecharsky and Gschneidner Jr. [3]).

\section{Physical model of magnetic refrigerator}

The operating cycle of the magnetic refrigerator is simulated to predict and optimise the performance. The five main components of the magnetic refrigerator i.e. regenerator, permanent magnet assembly (magnetic field source), heat exchangers and displacer are modelled as shown in Figure 2. The schematic of fluid flow and heat transfer through one channel of the multi-MCM regenerator are shown in Figure 3. The magnetization and demagnetization occur in the regenerator when there is a relative motion between the magnet and regenerator. The temperature of the MCM rises during magnetisation while it drops during demagnetisation. The fluid flow occurs in between magnetisation and demagnetisation. The CHEX and HHEX are concentric tube heat exchangers. Water is used as the working fluid.

To simplify, the following assumptions and approximations are made:

1) Magnetic field is uniform in the regenerator and the demagnetizing field is neglected;

2) Thermal and magnetic hystereses of MCM are negligible;

3) Properties of the MCM are independent of temperature and magnetic field intensity;

4) Flow is incompressible;

5) Thermophysical properties of the working fluid are taken to be constant;

6) Viscous dissipation is neglected; 
7) Heat loss to the ambient is neglected;

8) There are no fluid leakages in loops;

9) The dead volume of fluid inside the entire system is zero.

\subsection{Column Figure}

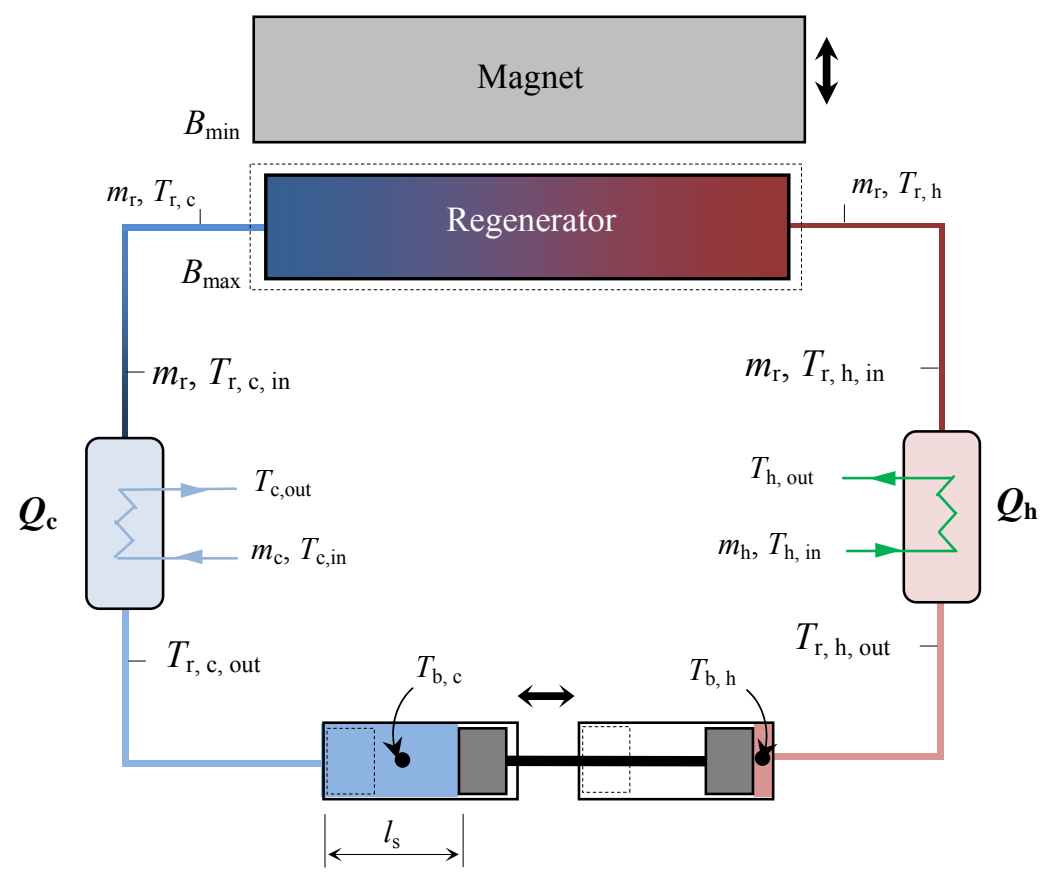

Figure 2 Simulation model of the magnetic refrigerator

\section{Mathematical model}

In this section, the mathematical models for the conjugated transfer in regenerator, magnetic field source (MCE), heat transfer in the heat exchangers and fluid displacer are presented.

\subsection{Regenerator}

Figure 3(a) shows the schematic of a multi-MCM microchannel regenerator which has the width $W$, height $H$ and length $L$. The regenerator is split along its length into n number of sections of equal length $L / \mathrm{n}$ as shown in Figure 3(b). Each section corresponds to a separate MCM with different Curie temperature. Considering symmetry, conjugated conductive heat transfer in the MCM wall and convective heat transfer in one channel are simulated. The $x$-coordinate is taken at the centre of the channel from the cold end. A photograph of the manufactured microchannel regenerator made of $\mathrm{Gd}$ is presented in Figure 4. 


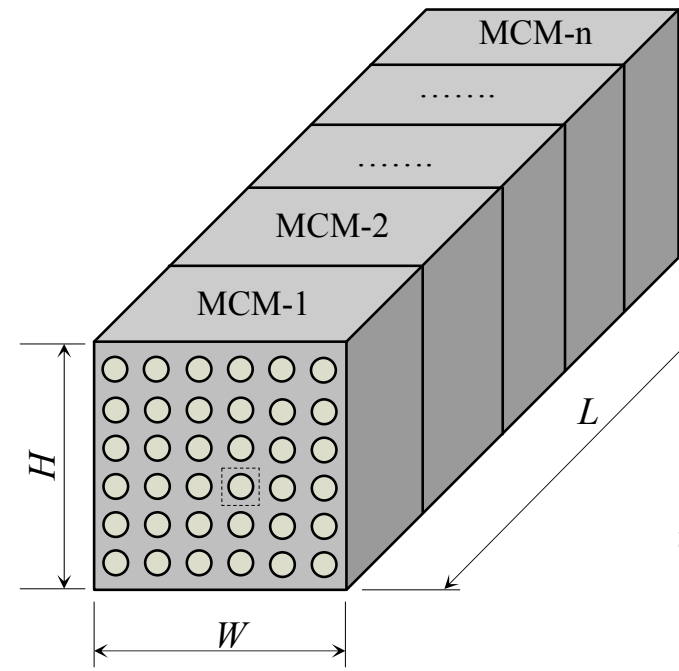

(a)

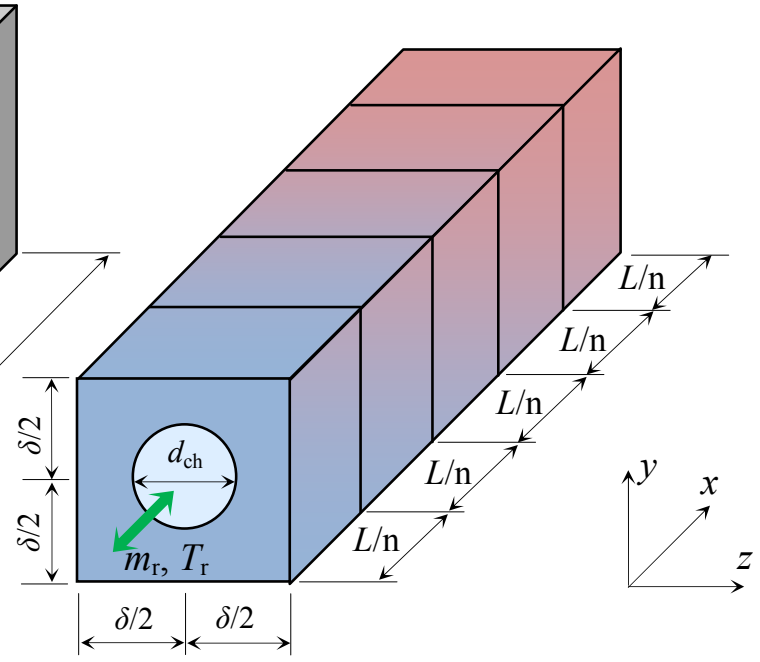

(b)

Figure 3 (a) Schematic of the multi-MCM microchannel regenerator; (b) Schematic of one channel simulated in this work.

\section{Single Column Figure}

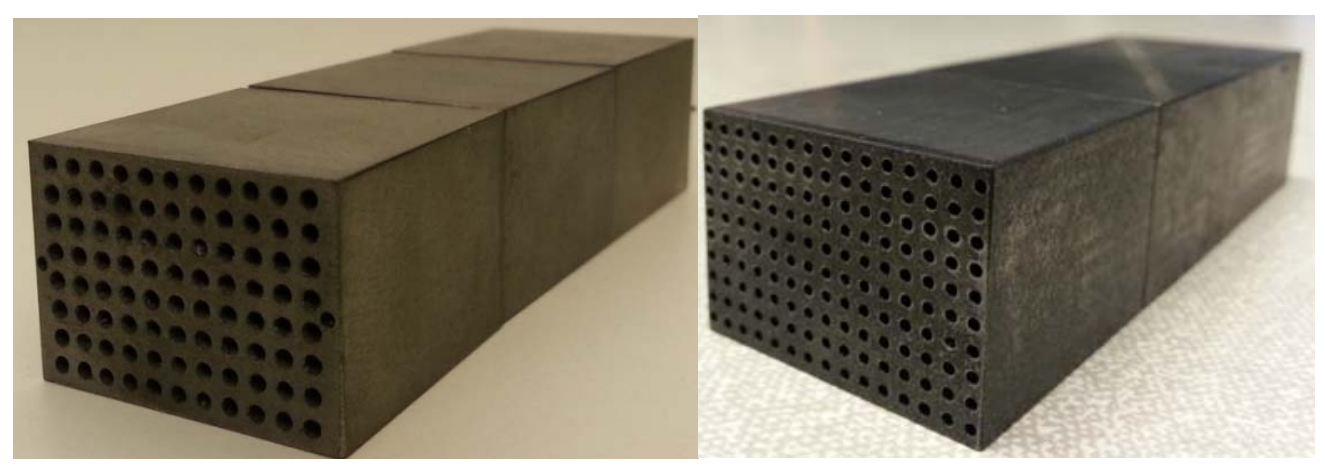

Figure 4 A photograph of the manufactured microchannel regenerator

The conservations of mass, momentum and energy are written as:

$$
\begin{aligned}
& \nabla \cdot \boldsymbol{u}=0 \\
& \rho_{\mathrm{f}}\left(\frac{\partial \boldsymbol{u}}{\partial t}+\boldsymbol{u} \cdot \nabla \boldsymbol{u}\right)=-\nabla P+\mu_{\mathrm{f}}\left(\nabla^{2} \boldsymbol{u}\right) \\
& \frac{\partial T_{\mathrm{f}}}{\partial t}+\boldsymbol{u} \cdot \nabla T_{\mathrm{f}}=\alpha_{\mathrm{f}}\left(\nabla^{2} T_{\mathrm{f}}\right) \\
& \frac{\partial T_{\mathrm{s}}}{\partial t}=\alpha_{\mathrm{s}}\left(\nabla^{2} T_{\mathrm{s}}\right)
\end{aligned}
$$


where $\boldsymbol{u}$ is the velocity of water, $t$ is time, $T_{\mathrm{f}}$ and $T_{\mathrm{s}}$ are temperatures of water and MCM solid, respectively, $\rho_{\mathrm{f}}, \mu_{\mathrm{f}}$ and $\alpha_{\mathrm{f}}$ are the density, dynamic viscosity and diffusivity of water, respectively, and $\alpha_{\mathrm{s}}$ is the diffusivity of the MCM solid.

The boundary conditions are:

$$
\begin{array}{lll}
q=0, u=v=w=0 & \text { at } & x=0, x=L \quad \text { and } y^{2}+z^{2}-d^{2} / 4>0 \\
\lambda_{\mathrm{f}}\left(\frac{\partial T_{\mathrm{f}}}{d \mathbf{n}}\right)=\lambda_{\mathrm{s}}\left(\frac{\partial T_{\mathrm{s}}}{d \mathbf{n}}\right) & \text { at } & 0 \leq x \leq L, y^{2}+z^{2}-d^{2} / 4=0 \\
\frac{\partial T_{\mathrm{s}}}{d \mathbf{n}}=0 & \text { at } & 0 \leq x \leq L, y=\delta / 2,-\delta / 2<z<\delta / 2 \\
\frac{\partial T_{\mathrm{s}}}{d \mathbf{n}}=0 & \text { at } & 0 \leq x \leq L,-\delta / 2<y<\delta / 2, z=\delta / 2
\end{array}
$$

Cold blow (for $t=t_{3}-t_{4}$, see Figure 5)

$$
\begin{array}{lll}
u_{\mathrm{r}, \mathrm{c}}=\frac{m_{\mathrm{r}}}{\rho_{\mathrm{f}} A_{\mathrm{ch}} n_{\mathrm{ch}}}, T_{\mathrm{r}, \mathrm{c}}=T_{\mathrm{r}, \mathrm{c}, \text { in }} & \text { at } & x=0, y^{2}+z^{2}-d^{2} / 4<0 \\
\frac{\partial \mathbf{u}}{\partial \mathbf{n}}=0, \frac{\partial T_{\mathrm{f}}}{\partial \mathbf{n}}=0 & \text { at } & x=L, y^{2}+z^{2}-d^{2} / 4<0
\end{array}
$$

Hot blow (for $t=t_{6}-t_{7}$, see Figure 5)

$$
\begin{array}{lll}
u_{\mathrm{r}, \mathrm{h}}=\frac{m_{\mathrm{r}}}{\rho_{\mathrm{f}} A_{\mathrm{ch}} n_{\mathrm{ch}}}, T_{\mathrm{r}, \mathrm{h}}=T_{\mathrm{r}, \mathrm{h}, \text { in }} & \text { at } & x=L, y^{2}+z^{2}-d^{2} / 4<0 \\
\frac{\partial \mathbf{u}}{\partial \mathbf{n}}=0, \frac{\partial T_{\mathrm{f}}}{\partial \mathbf{n}}=0 & \text { at } & x=0, y^{2}+z^{2}-d^{2} / 4<0
\end{array}
$$

The MCE is implemented using the discrete method [25]. During the processes of magnetization and demagnetization, local temperature at the time $t^{\mathrm{n}+1}\left(t^{\mathrm{n}+1}=t^{\mathrm{n}}+\Delta t\right)$ takes a value at the time $t^{\mathrm{n}}$ with an instantaneous temperature jump calculated by Eq. (13).

$$
T_{\mathrm{s}}\left(x, y, z, t^{\mathrm{n}+1}\right)=T_{\mathrm{s}}\left(x, y, z, t^{\mathrm{n}}\right) \pm \Delta T_{\mathrm{ad}}\left[T_{\mathrm{s}}\left(x, y, z, t^{\mathrm{n}}\right), \Delta B\right]
$$


where $T_{\mathrm{s}}\left(x, y, z, t^{\mathrm{n}+1}\right)$ and $T_{\mathrm{s}}\left(x, y, z, t^{\mathrm{n}}\right)$ represent temperatures in solid MCM at location $(x, y, z)$ and times $t^{\mathrm{n}+1}$ and $t^{\mathrm{n}}$, respectively, $\Delta T_{\mathrm{ad}}$ is positive during magnetization and negative during demagnetization. The adiabatic temperature change is determined by Eq. (14) [1].

$$
\Delta T_{\mathrm{ad}}\left(B, T_{\mathrm{s}}\right)=-\int_{B_{\min }}^{B_{\max }} \frac{T_{\mathrm{s}}}{c_{\mathrm{P}, \mathrm{s}}\left(B, T_{\mathrm{s}}\right)} \frac{\partial m}{\partial T} d B
$$

where $c_{\mathrm{P}, \mathrm{s}}(B, T)$ is the heat capacity of the $\mathrm{MCM}$, and is the sum of the lattice $c_{\text {lat }}(T)$, electronic $c_{\text {ele }}(T)$ and magnetic $c_{\text {mag }}(B, T)$ heat capacities as given below:

The calculation of the MCE using the mean field model $[17,20]$ involves iterative solution for a set of non-linear equations and it can be computationally expensive for a $3 \mathrm{D}$ computational domain. To expedite the computation of the dynamic heat pump/refrigerator system, polynomial fit was applied to correlate $\Delta T_{\mathrm{ad}}$ and $T_{\mathrm{s}}$. For a given magnetic field intensity, $\Delta T_{\mathrm{ad}}$ is solely a function of local temperature $T_{\mathrm{s}}$ of the solid. Two polynomials (Eqs. (15) and (16)) were found for temperatures lower and higher the Curie temperature $\left(T_{\mathrm{Cu}}=294.0 \mathrm{~K}\right)$. Equations $(15)$ and $(16)$ are used in the present simulation.

$$
\begin{array}{ll}
\Delta T_{\mathrm{ad}}\left(T_{\mathrm{s}}, \Delta B=1.0 \mathrm{~T}\right)=a_{1} T_{\mathrm{s}}^{3}+a_{2} T_{\mathrm{s}}^{2}+a_{3} T_{\mathrm{s}}+a_{4} & \text { for } T_{\mathrm{s}} \leq T_{\mathrm{Cu}} \\
\Delta T_{\mathrm{ad}}\left(T_{\mathrm{s}}, \Delta B=1.0 \mathrm{~T}\right)=b_{1} T_{\mathrm{s}}^{3}+b_{2} T_{\mathrm{s}}^{2}+b_{3} T_{\mathrm{s}}+b_{4} & \text { for } T_{\mathrm{s}}>T_{\mathrm{Cu}}
\end{array}
$$

Figure 5(a) shows the variation of $\Delta T_{\mathrm{ad}}$ with temperature for $\mathrm{Gd}\left(T_{\mathrm{Cu}}=294 \mathrm{~K}\right)$ and two hypothetical materials with Curie temperatures at $289 \mathrm{~K}$ and $284 \mathrm{~K}$, respectively. Use of three $\mathrm{MCM}$ regenerator would be able to provide a temperature jump of $\sim 3 \mathrm{~K}$ over a temperature range of $\sim 15 \mathrm{~K}$ while for single material this range is limited to just $\sim 5 \mathrm{~K}$.

Various $\Delta T_{\mathrm{ad}}$ profiles for different MCMs are shown in Figure 5(b). The $\Delta T_{\mathrm{ad}}$ curves for different hypothetical materials are obtained by shifting the curve peak of $\Delta T_{\text {ad }}$ profile of Gd from 294.0 K to desired temperatures for $\Delta B=1.0 \mathrm{~T}$. Polynomial fit was applied to correlate $\Delta T_{\text {ad }}$ and $T_{\mathrm{s}}$ and two polynomials are obtained for each MCM. Similar polynomial fittings have also been 
applied for different $\Delta T_{\text {ad }}$ vs $T_{\mathrm{s}}$ curves plotted in Figure 5(b) and the polynomial coefficients of each material are listed in Table 1.

\section{Single Column Figure}
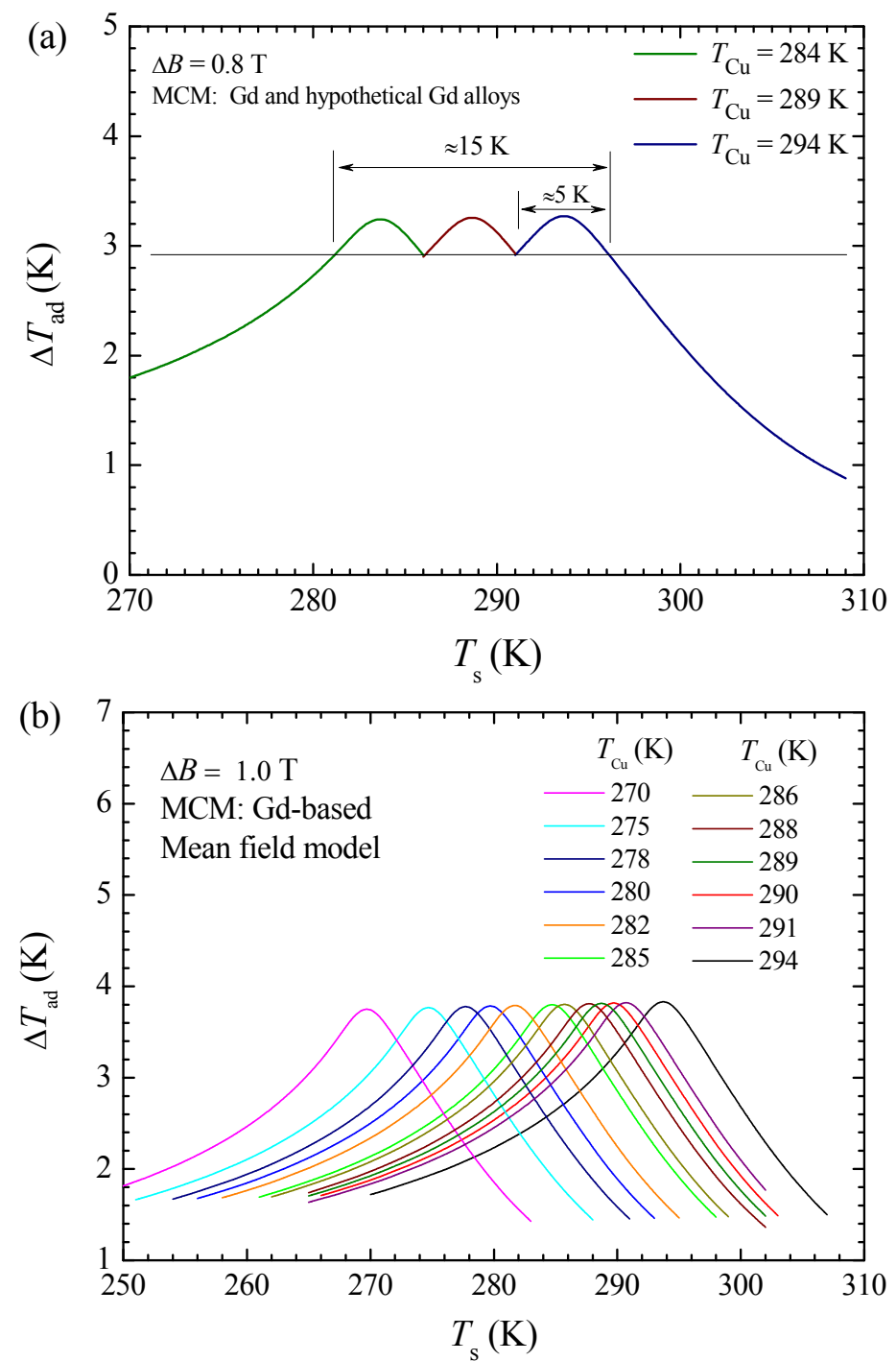

Figure 5 Variation of $\Delta T_{\text {ad }}$ with temperature for different values of $\Delta B$ and Curie temperatures predicted by mean field model (Morrish).

Table 1 Coefficients in Eqs. (15) and (16) for different Curie temperatures and magnetic field intensity $\Delta B$ $=1.0 \mathrm{~T}$.

\begin{tabular}{|c|c|c|c|c|c|c|c|c|}
\hline \multirow{3}{*}{$\begin{array}{c}T_{\mathrm{Cu}} \\
\mathrm{K}\end{array}$} & \multicolumn{8}{|c|}{ Polynomial coefficients } \\
\hline & \multicolumn{4}{|c|}{$T_{\mathrm{s}} \leq T_{\mathrm{Cu}}$} & \multicolumn{4}{|c|}{$T_{\mathrm{s}}>T_{\mathrm{Cu}}$} \\
\hline & $a_{1}$ & $a_{2}$ & $a_{3}$ & $a_{4}$ & $b_{1}$ & $b_{2}$ & $b_{3}$ & $b_{4}$ \\
\hline 270 & $7.802838 \times 10^{-5}$ & $-5.721281 \times 10^{-2}$ & 14.020955 & $-1.146817 \times 10^{3}$ & $-5.395199 \times 10^{-5}$ & $5.020467 \times 10^{-2}$ & -15.574492 & $1.611033 \times 10^{3}$ \\
\hline 275 & $7.722034 \times 10^{-5}$ & $-5.775379 \times 10^{-2}$ & 14.435696 & $-1.204251 \times 10^{3}$ & $-5.283248 \times 10^{-5}$ & $5.002822 \times 10^{-2}$ & -15.791982 & $1.662083 \times 10^{3}$ \\
\hline 280 & $7.641005 \times 10^{-5}$ & $-5.826873 \times 10^{-2}$ & 14.848947 & $-1.262897 \times 10^{3}$ & $-5.173429 \times 10^{-5}$ & $0.983648 \times 10^{-2}$ & -16.002893 & $1.713240 \times 10^{3}$ \\
\hline 285 & $7.565805 \times 10^{-5}$ & $-5.880683 \times 10^{-2}$ & 15.273674 & $-1.323920 \times 10^{3}$ & $-5.056740 \times 10^{-5}$ & $4.955020 \times 10^{-2}$ & -16.183475 & $1.762122 \times 10^{3}$ \\
\hline 290 & $7.486439 \times 10^{-5}$ & $-5.928784 \times 10^{-2}$ & 15.688048 & $1.385368 \times 10^{3}$ & $-4.952326 \times 10^{-5}$ & $4.934121 \times 10^{-2}$ & -16.384612 & $1.813737 \times 10^{3}$ \\
\hline 282 & $7.609028 \times 10^{-5}$ & $-5.847142 \times 10^{-2}$ & 15.014828 & $1.286783 \times 10^{3}$ & $-5.121935 \times 10^{-5}$ & $4.968313 \times 10^{-2}$ & -16.063928 & $1.731606 \times 10^{3}$ \\
\hline
\end{tabular}

\subsection{Heat exchangers}


The heat exchangers at the cold and hot ends of the regenerator have been simulated using $\varepsilon$ $N T U$ method [26]. The flow arrangement in the heat exchangers is set to be counter-current when fluid enters the heat exchanger from the regenerator side and becomes parallel when the flow direction is reversed. The heat transfer rates at the HHEX and CHEX, the heating and cooling loads, can be calculated by Eq. (17).

$$
Q_{\mathrm{j}}=\frac{1}{\tau} \int_{0}^{\tau} m_{\mathrm{j}} c_{P, \mathrm{j}}\left(T_{\mathrm{j}, \text { out }}-T_{\mathrm{j}, \text { in }}\right) \mathrm{d} t
$$

where $m_{\mathrm{j}}$ is the mass flow rate, $T_{\mathrm{j}, \text { out }}$ and $T_{\mathrm{j}, \text { in }}$ are the temperatures at the outlet and inlet, respectively, $c_{P, \mathrm{j}}$ is the specific heat capacity of the fluid, $\tau$ is the period of a cycle. Here subscript $\mathrm{j}$ refers to hot or cold i.e. h or c. The temperature at the inlet of the heat exchanger $T_{\mathrm{j}, \text { in }}$ is determined from numerical solution at the exit of the regenerator, while the temperature at the outlet $T_{\mathrm{j}, \text { out }}$ is calculated using $\varepsilon-N T U$ method (Cengel [27]).

For $R e<2300$, Gnielinski [28] correlation is used,

$$
N u=\frac{\left(f_{\mathrm{D}} / 8\right)(R e-1000) P r}{1+12.7 \sqrt{f_{\mathrm{D}} / 8}\left(\operatorname{Pr}^{2 / 3}-1\right)}
$$

where $f$ is the Darcy friction factor calculated by the Filonenko [29] correlation.

$$
f_{\mathrm{D}}=(1.58 \ln R e-3.28)^{-2}
$$

Equation (18) is valid in the ranges of $\operatorname{Re}=2300 \sim 10^{6}, \operatorname{Pr}=0.6 \sim 10^{5}$.

For laminar flow $(\operatorname{Re}<2300)$,

$$
\begin{aligned}
N u & =3.66 \\
f_{\mathrm{D}} & =64 / R e
\end{aligned}
$$

\subsection{Displacer}

Due to the horizontal reciprocating motion of the piston, the mass flow rate of the working fluid is determined by

$$
m_{\mathrm{r}}=\frac{1}{2} \pi \rho_{\mathrm{f}} d_{\mathrm{p}}^{2} R f \sin (2 \pi f t)
$$


where $R$ is the radius of the crank disk of the displacer $\left(l_{\mathrm{s}}=2 R\right), f$ is the rotational frequency of the crank disk and $d_{\mathrm{p}}$ is the cross-sectional diameter of the cylinder.

The average mass flow rate during the cold or hot blows is determined as

$$
m_{\mathrm{r}, \mathrm{av}}=\frac{1}{\tau_{\text {flow }}} \int_{0}^{\tau_{\text {flow }}} m_{\mathrm{r}}(t) \mathrm{d} t
$$

Assuming instant mixing of the fluid inside the chamber, the enthalpy-averaged bulk temperature $T_{\mathrm{b}, \mathrm{j}}$ of the fluid inside the chamber is calculated by

$$
T_{\mathrm{b}, \mathrm{j}}=\frac{\int_{0}^{\tau_{\text {flow }}} m_{\mathrm{r}}(t) T_{\mathrm{r}, \mathrm{j}, \text { out }} \mathrm{d} t}{\int_{0}^{\tau_{\text {flow }}} m_{\mathrm{r}}(t) \mathrm{d} t}
$$

Utilization, which is the ratio of thermal mass of fluid to thermal of solid, can be defined as

$$
\varphi=\frac{m_{\mathrm{r}, \mathrm{av}} c_{\mathrm{P}, \mathrm{f}} \tau_{\mathrm{f}}}{m_{\mathrm{s}} c_{\mathrm{P}, \mathrm{s}}}
$$

where $\tau_{\mathrm{f}}$ is the time period for cold/hot blow and $m_{\mathrm{s}}$ is the mass of the magnetocaloric material.

\subsection{Computation scheme}

The procedure starts by creating 3D geometry and grid for the regenerator and defining the operating parameters such as the magnetic field intensity, the cycle frequency (hot and cold blow durations, magnetisation and demagnetisation durations) and the mass flow rate. The initial temperature (at $t=0 \mathrm{~s}$ ) of the regenerator solid and the fluid inside the entire system is taken to be 293.0 K. The mass flow rate and magnetic field profiles are shown in Figure 6. The grid independence of the numerical results was achieved by varying the number of divisions along $x, y$ and $z$ directions for single blow steady state conjugated heat transfer in a channel. A summary is presented in Table 2. The width, height and length of the solid having a microchannel of diameter $d_{\mathrm{ch}}$ (see Figure 3(b)) are considered to be $\delta_{x}, \delta_{y}$ and $L$, respectively. The number of divisions along $x$, $y$ and $z$ directions are represented by $n_{\Delta x}, n_{\Delta y}$ and $n_{\Delta z}$, respectively. The total number of control volumes are given by $n_{\mathrm{CV}}$. The avergae Nusselt number was calculated for different mesh sizes. The mesh with $10 \times 10 \times 90$ divsions was selected for the present numerical simulation. 
Equations (1) to (4) together with boundary conditions (Eqs. (5) - (12)) were numerically solved using Fluent. The SIMPLE algorithm was chosen. The simulations of the regenerator, calculations of CHEX and HHEX, mass flow rate of the working fluid by the displacer as well as the MCE caused by the magnetic field source were all coupled together with the help of user defined functions (UDF).

\section{Single Column Figure}

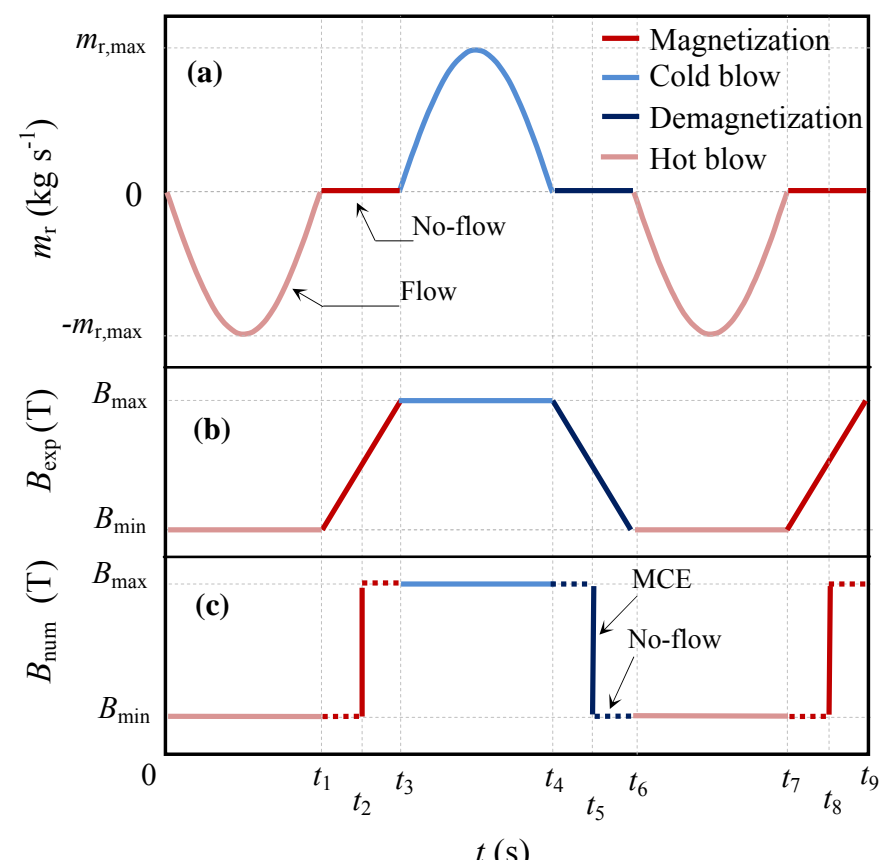

Figure 6 Variations of (a) $m_{\mathrm{r}}$, (b) $B_{\exp }$ and (c) $B_{\text {num }}$ with time $t$

Table 2 Mesh independence study at $\delta_{x} / d=\delta_{y} / d=1.5, L / d=90, \operatorname{Re}=500, \operatorname{Pr}=7.0$

\begin{tabular}{ccccc}
\hline$n_{\Delta x}$ & $n_{\Delta y}$ & $n_{\Delta z}$ & $n_{\mathrm{CV}}$ & $N u_{\mathrm{av}}$ \\
\hline 8 & 8 & 60 & 24480 & 5.71 \\
8 & 8 & 90 & 36720 & 5.70 \\
8 & 8 & 120 & 46080 & 5.58 \\
8 & 8 & 150 & 57600 & 5.59 \\
10 & 10 & 60 & 37200 & 5.59 \\
\hline 10 & 10 & 90 & 55800 & 5.57 \\
\hline 10 & 10 & 120 & 74400 & 5.55 \\
10 & 10 & 150 & 93000 & 5.64 \\
15 & 15 & 60 & 48960 & 5.59 \\
15 & 15 & 90 & 73440 & 5.57 \\
15 & 15 & 120 & 97920 & 5.55 \\
15 & 15 & 150 & 122400 & 5.54 \\
\hline
\end{tabular}

\section{Results and discussion}


The models and code validation and parametric study to optimise system performance are carried out. The results are discussed below.

\subsection{Comparison with experimental data}

The validation of the present numerical method for multiple-MCM regenerator is performed by comparing the simulation results with the experimental data of Tusek et al. [10] and Legait et al. [11] parallel-plate regenerators made of four different $\mathrm{LaFe}_{13-\mathrm{x}-\mathrm{y}} \mathrm{Co}_{\mathrm{x}} \mathrm{Si}_{\mathrm{y}}$ compounds. Figure 7(a) shows the physical model of parallel-plate regenerator with four MCMs. The variation of $\Delta T_{\text {ad }}$ with temperature for the cases of Tusek et al. [10] and Legait et al. [11] are shown in Figure 7(b) and $7(c)$.

\section{Single Column Figure}

(a)
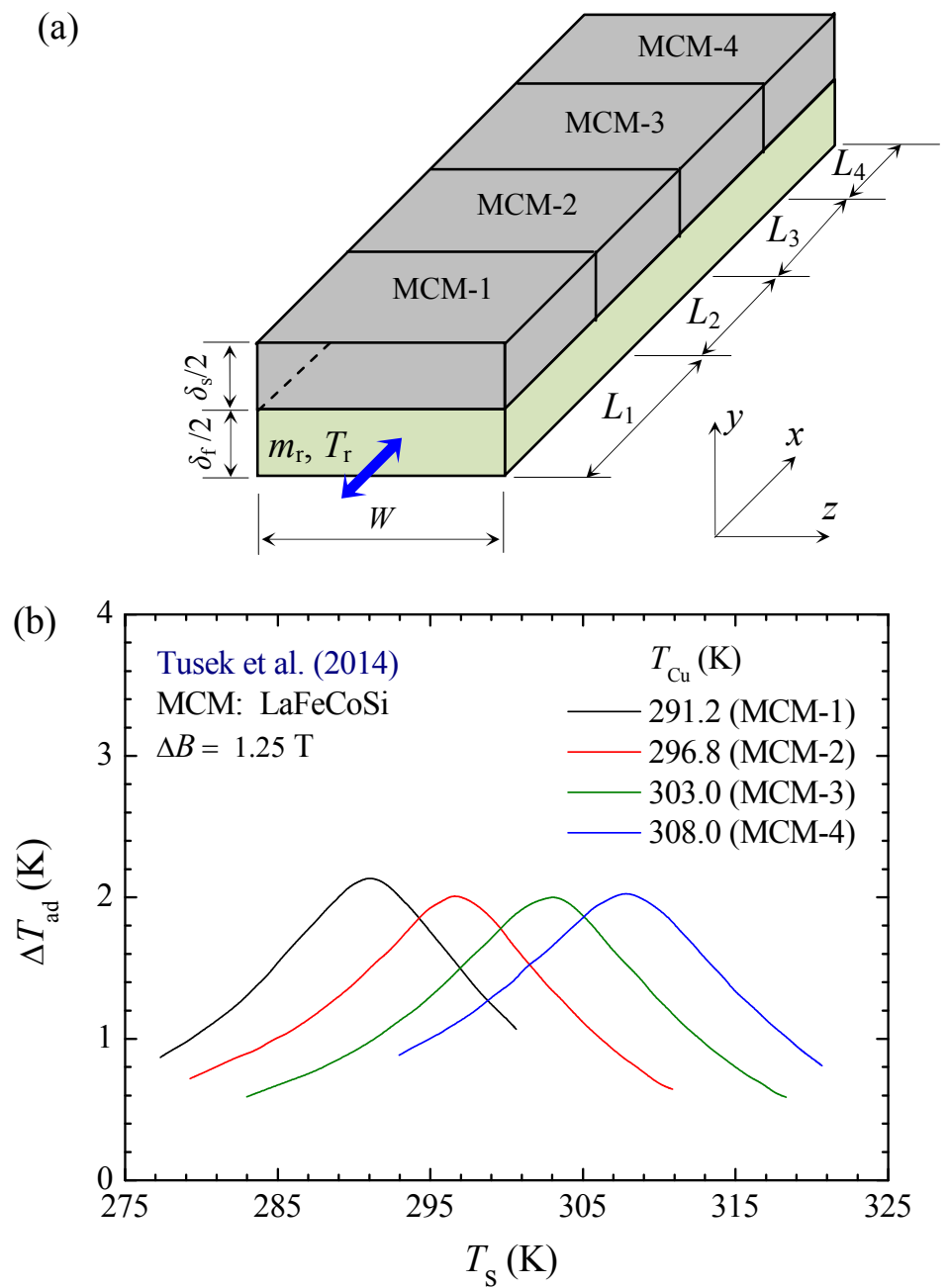


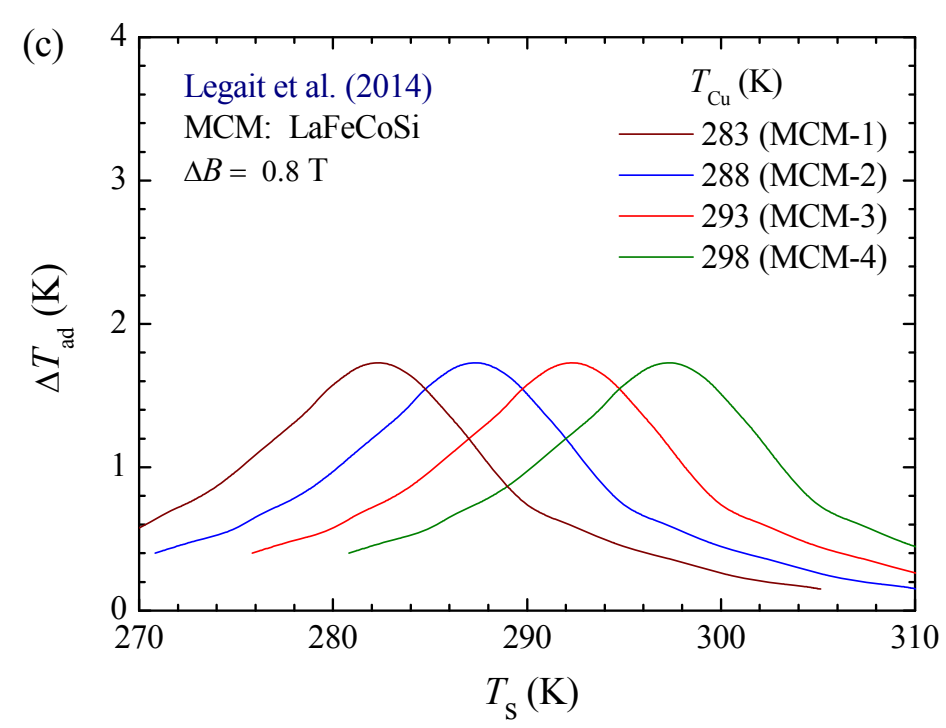

Figure 7 (a) Physical model of the parallel-plate regenerator with 4 MCMs; (b) Variation of $\Delta T_{\text {ad }}$ with temperature for four $\mathrm{LaFe}_{13-\mathrm{x}-\mathrm{y}} \mathrm{Co}_{\mathrm{x}} \mathrm{Si}_{\mathrm{y}}$ compounds with different $T_{\mathrm{Cu}}$ used in experiment by Tusek et al. [10] with $T_{\mathrm{Cu}}=291.2,296.8,303.0$ and $308.0 \mathrm{~K}$; (c) Variation of $\Delta T_{\text {ad }}$ with temperature for four $\mathrm{LaFe}_{13-\mathrm{x}-\mathrm{y}} \mathrm{Co}_{\mathrm{x}} \mathrm{Si}_{\mathrm{y}}$ compounds used in experiment by Legait et al. [11] with $T_{\mathrm{Cu}}=283,288,293$ and $298 \mathrm{~K}$.

Legait et al. [11] conducted experimental investigations of single and multi-MCM parallel-plate regenerators made of different alloys of $\mathrm{LaFe}_{13-\mathrm{x}-\mathrm{y}} \mathrm{Co}_{\mathrm{x}} \mathrm{Si}_{\mathrm{y}}$. Figure 8 compares the no-load temperature spans for the experimental data of Legait et al. [11] and the present numerical results under same operating conditions. The simulation was initialised with a linear initial gradient in the regenerator solid and channel to save computational time. Figure 8(a) shows the transient development of temperature span for $\varphi=0.1$. The steady-state temperature span of $\sim 13 \mathrm{~K}$ is predicted by the model while the corresponding experimental value is $\sim 10.5 \mathrm{~K}$. It can be seen that the model can predict results within an average difference of $25 \%$ from the experimental data.

\section{Single Column Figure}




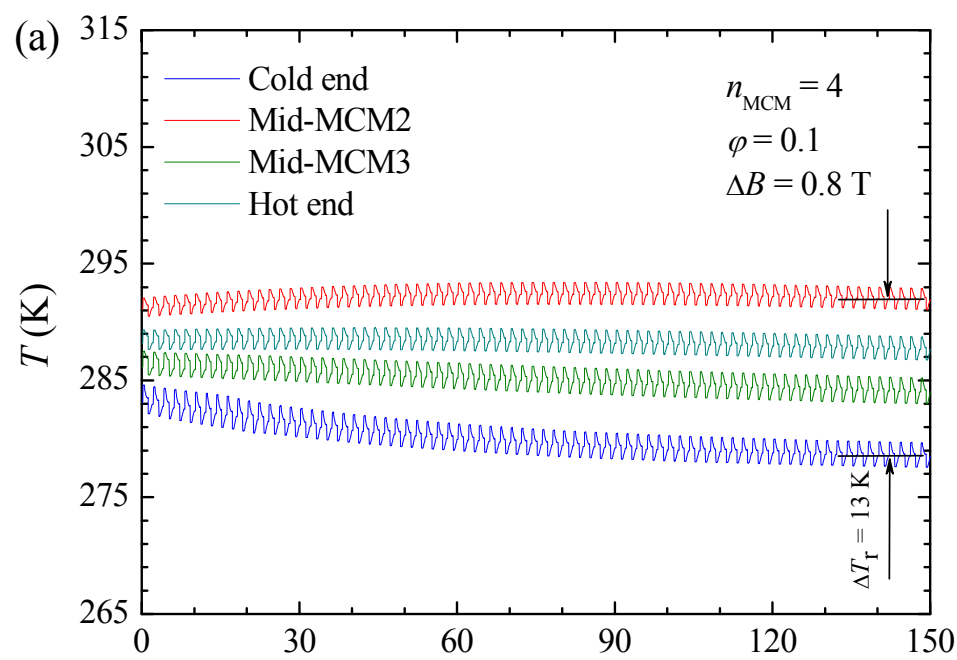

$t(\mathrm{~s})$

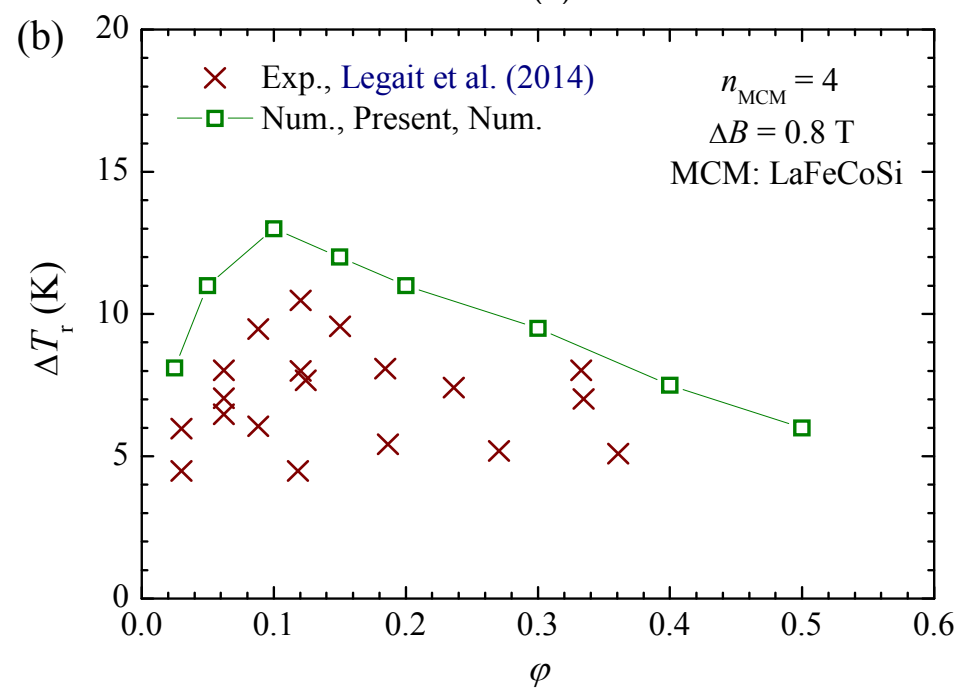

Figure 8 Comparison of the present results with experimental data of Legait et al. [11] with four $\mathrm{LaFe}_{13-\mathrm{x}-}$ ${ }_{\mathrm{y}} \mathrm{Co}_{\mathrm{x}} \mathrm{Si}_{\mathrm{y}}$ compounds having $T_{\mathrm{Cu}}=283,288,293$ and $298 \mathrm{~K}$ : (a) no-load temperature for $\varphi=0.1$; (b) variation of temperature span with utilization.

Similarly, numerical results are compared with the experimental data of Tusek et al. [10] for four MCM based parallel plate regenerator and presented in Figure 9. The transient response of four-MCM regenerator for $\varphi=0.1$ is shown in Figure 9(a) giving a temperature span of $\sim 23 \mathrm{~K}$. The no-load temperature spans predicted by numerical model are plotted with the experimental results of Tusek et al. [10] in Figure 9(b). The maximum difference between the numerical predictions and the experimental data is $\sim 30 \%$. The main sources causing the deviation of numerical results from the experimental data are the assumptions of negligible parasitic heat losses to surrounding, absence of internal demagnetising field and few other simplifications made in the development of the present model. Also, the MCE calculated using the mean field model is slightly larger than the 
corresponding experimental values and this it is another cause of the over-predicted numerical results.

\section{Single Column Figure}
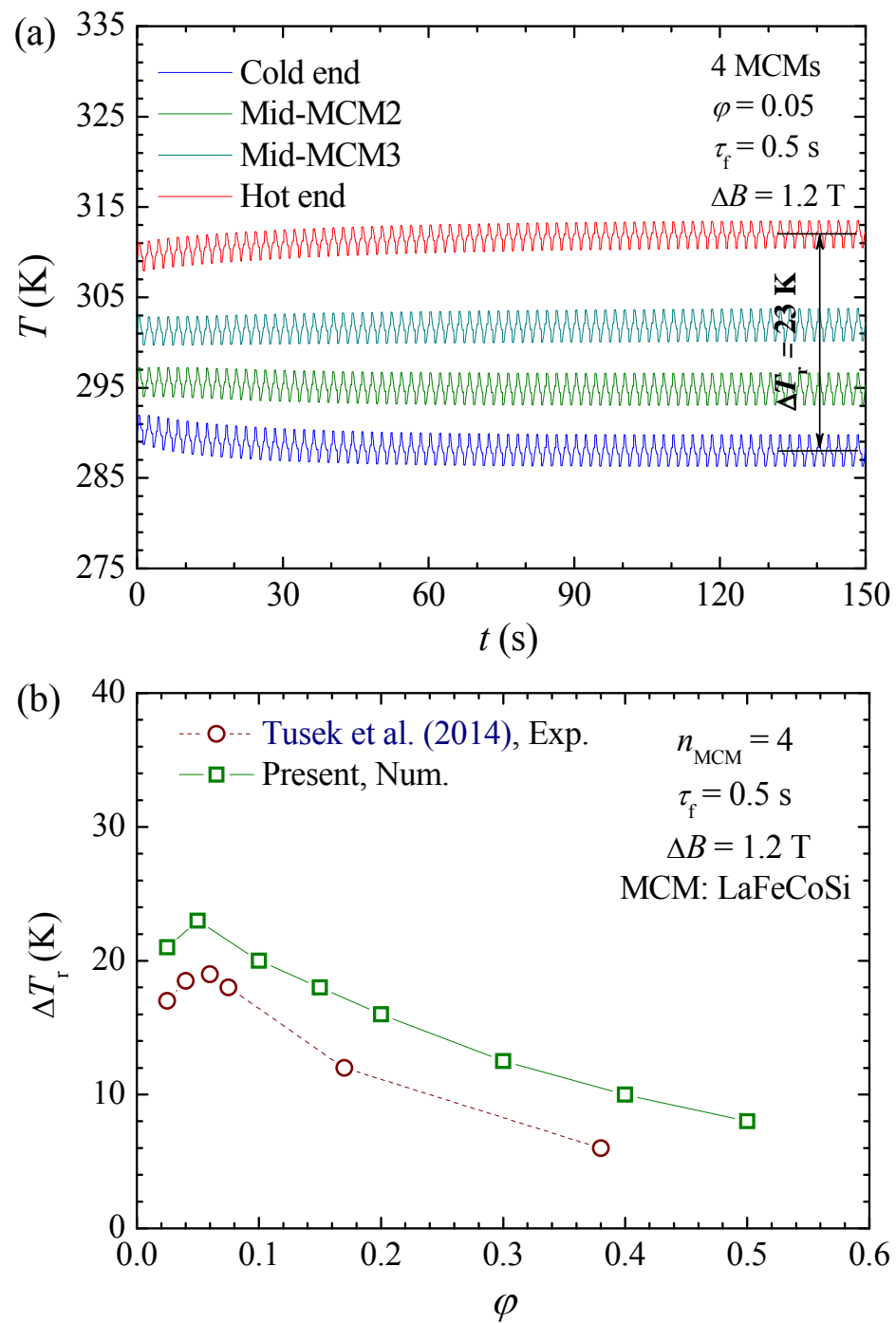

Figure 9 Comparison of the present results with experimental data of Tusek et al. [10] with four $\mathrm{LaFe}_{13-\mathrm{x}-}$ ${ }_{\mathrm{y}} \mathrm{Co}_{\mathrm{x}} \mathrm{Si}_{\mathrm{y}}$ compounds having $T_{\mathrm{Cu}}=291.2,296.8,303.0$ and $308.0 \mathrm{~K}$; (a) no-load temperature for $\varphi=0.05$; (b) variation of temperature span with utilization.

An estimation of the heat losses to environment is made using the following set of equations (Nielsen et al. [30]).

$$
Q=\frac{\Delta T}{R_{\text {tot }}}
$$


where $\Delta T$ is the temperature difference between the local temperature of the MCM regenerator $T_{\mathrm{r}, \mathrm{i}}$ along the flow direction and the ambient temperature $T_{\infty}$.

$$
R_{\mathrm{tot}}=R_{\mathrm{MCM}}+R_{\text {hou. }}+R_{\text {conv. }}
$$

where $R_{\mathrm{MCM}}$ and $R_{\text {hou. }}$ are the conductive thermal resistances of the MCM and the regenerator housing respectively and $R_{\text {Conv }}$ is the convective resistance. The thermal conductivity of the MCM is taken as $10.6 \mathrm{Wm}^{-1} \mathrm{~K}^{-1}$ (that of $\mathrm{Gd}$ ) and for the regenerator housing the thermal conductivity is $0.2 \mathrm{Wm}^{-1} \mathrm{~K}^{-1}$ for the calculation of $R_{\mathrm{MCM}}$ and $R_{\mathrm{hou}}$. The value of natural convection coefficient is taken as $15 \mathrm{Wm}^{-2} \mathrm{~K}^{-1}$ to calculate $R_{\text {conv }}$ (Cengel [27], Holman [31]).

Figure 10 shows the comparison of the present simulation results with and without heat losses and the experimental data of Tusek et al. [10]. It can be seen that with the inclusion of the heat losses in the present numerical model, the maximum difference between the experimental and numerical results reduces to $\sim 15 \%$.

\section{Single Column Figure}

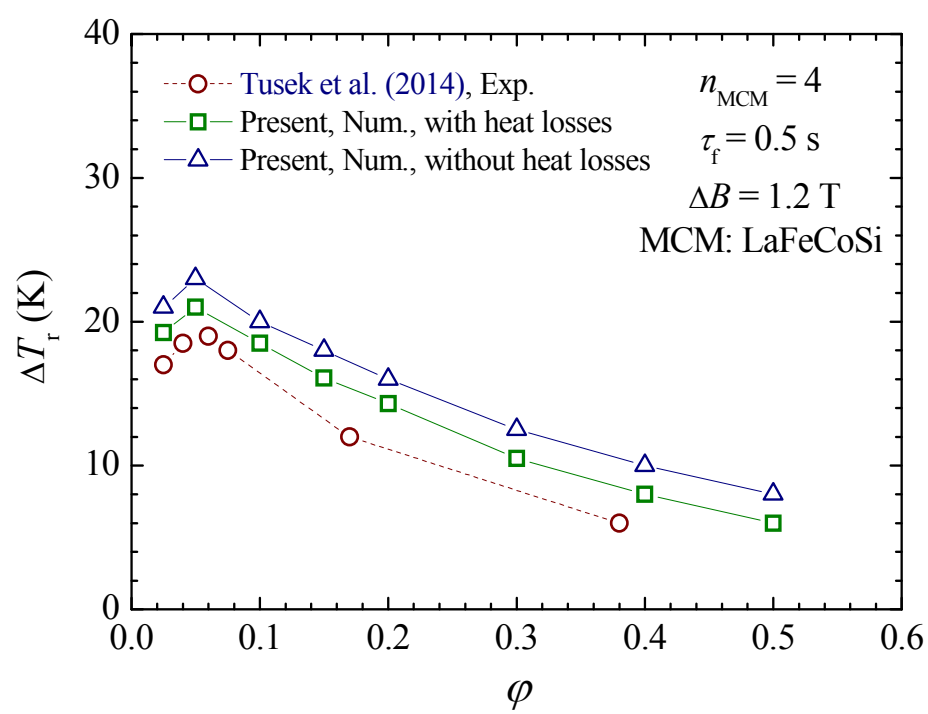

Figure 10 Comparison of the present simulation results with and without heat losses and the experimental data of Tusek et al. [10] with four $\mathrm{LaFe}_{13-\mathrm{x}-\mathrm{y}} \mathrm{Co}_{\mathrm{x}} \mathrm{Si}_{\mathrm{y}}$ compounds having $T_{\mathrm{Cu}}=291.2,296.8,303.0$ and 308.0 $\mathrm{K}$.

\subsection{Parametric study on microchannel regenerator}

Microchannel regenerator shown in Figure $\mathbf{3}$ is used in the following sections to predict the performance under different geometric dimensions and operating conditions. The operating and 
geometric conditions for various components of the magnetic refrigerator model are listed in Table 3. Two cases of the microchannel regenerator A and B are summarised in Table 4. The overall regenerator size is taken as $30 \mathrm{~mm} \times 21 \mathrm{~mm} \times 90 \mathrm{~mm}$. The regenerator porosity $\varepsilon$ and the specific heat transfer area $a_{\mathrm{p}}$ are changed by changing microchannel diameter $d_{\mathrm{ch}}$, inter-channel (centre to centre) spacing $\delta_{\text {ch }}$ and number of channels $n_{\text {ch }}$ for the two cases.

Table 3 Dimensions and parameters for microchannel (MCM: Gd; overall dimensions $30 \mathrm{~mm} \times 21 \mathrm{~mm} \times 90$ $\mathrm{mm})$.

\begin{tabular}{ll}
\hline Component & Geometric/operating conditions \\
\hline Regenerator & Gd and its hyp. alloys, $21 \mathrm{~mm} \times 30 \mathrm{~mm} \times 90 \mathrm{~mm}, d_{\mathrm{ch}}=1.0 \mathrm{~mm}, 1.5 \mathrm{~mm}$. \\
Working fluid & Water, $\lambda_{\mathrm{f}}=0.6 \mathrm{Wm}^{-1} \mathrm{~K}^{-1}, c_{\mathrm{f}}=4180 \mathrm{Jkg}^{-1} \mathrm{~K}^{-1}, \rho_{\mathrm{f}}=1000.0 \mathrm{kgm}^{-3}$ \\
Auxiliary fluids & Water \\
Magnet & Material: NdFeB, size: $100 \mathrm{~mm} \times 50 \mathrm{~mm} \times 25 \mathrm{~mm}, \Delta B=0.8 \mathrm{~T}, 1.0 \mathrm{~T}$. \\
CHEX & $d_{\mathrm{i}, \mathrm{c}}=4.0 \mathrm{~mm}, d_{\mathrm{o}, \mathrm{c}}=6.0 \mathrm{~mm}, l_{\mathrm{c}}=250.0 \mathrm{~mm}, m_{\mathrm{c}}=250 \mathrm{gs}^{-1}$. \\
HHEX & $d_{\mathrm{i}, \mathrm{h}}=4.0 \mathrm{~mm}, d_{\mathrm{o}, \mathrm{h}}=6.0 \mathrm{~mm}, l_{\mathrm{h}}=250.0 \mathrm{~mm}, m_{\mathrm{h}}=250-500 \mathrm{gs}^{-1}$ \\
Displacer & Displacer: $d_{\mathrm{p}}=16 \mathrm{~mm}, l_{\mathrm{s}}=2 R=10-100 \mathrm{~mm}, \omega=\mathrm{f}(f)$ \\
\hline
\end{tabular}

Table 4 Dimensions and parameters for microchannel regenerators (MCM: Gd; overall dimensions $30 \mathrm{~mm} \times 21 \mathrm{~mm} \times 90 \mathrm{~mm}$ )

\begin{tabular}{cccccccc}
\hline Case & $\begin{array}{c}d_{\mathrm{ch}} \\
\mathrm{mm}\end{array}$ & $\begin{array}{c}\delta_{\mathrm{ch}} \\
\mathrm{mm}\end{array}$ & $n_{\mathrm{ch}}$ & $\begin{array}{c}d_{\mathrm{h}} \\
\mathrm{mm}\end{array}$ & $\varepsilon$ & $\begin{array}{c}a_{\mathrm{p}} \\
\mathrm{m}^{2} \mathrm{~m}^{-3}\end{array}$ & $\begin{array}{c}m_{\mathrm{s}} \\
\mathrm{g}\end{array}$ \\
\hline $\mathrm{A}$ & 1.0 & 1.2 & 400 & 1.0 & 0.50 & 1995 & 225 \\
$\mathrm{~B}$ & 1.5 & 1.7 & 176 & 1.5 & 0.50 & 1316 & 227 \\
\hline
\end{tabular}

\subsubsection{No load temperature span}

Figure 11(a) plots the transient development of temperature span for single and three-MCM regenerators. The Curie temperatures are taken to be $284.0 \mathrm{~K}, 289.0$ and $294.0 \mathrm{~K}$ and their respective $\Delta T_{\mathrm{ad}}-\mathrm{vs}-T_{\mathrm{s}}$ profiles are shown in Figure 5(a). As can be seen in Figure 11(a), a larger temperature span by $\sim 9 \mathrm{~K}$ is achieved using a three-MCM regenerator as compared to single-MCM regenerator at a cycle frequency of $2.0 \mathrm{~Hz}$. Figure 11(b) plots the variation of no-load temperature span with utilization for the two regenerators for $f=0.5 \mathrm{~Hz}$. The no-load temperature span decreases as the utilization is increased and the difference in the performance of two regenerators also decreases. The cooling capacity of the system is directly related to the established temperature 
span along the length of the regenerator. Thus, larger temperature span corresponds to improved performance of the magnetic refrigerator.

\section{Single Column Figure}
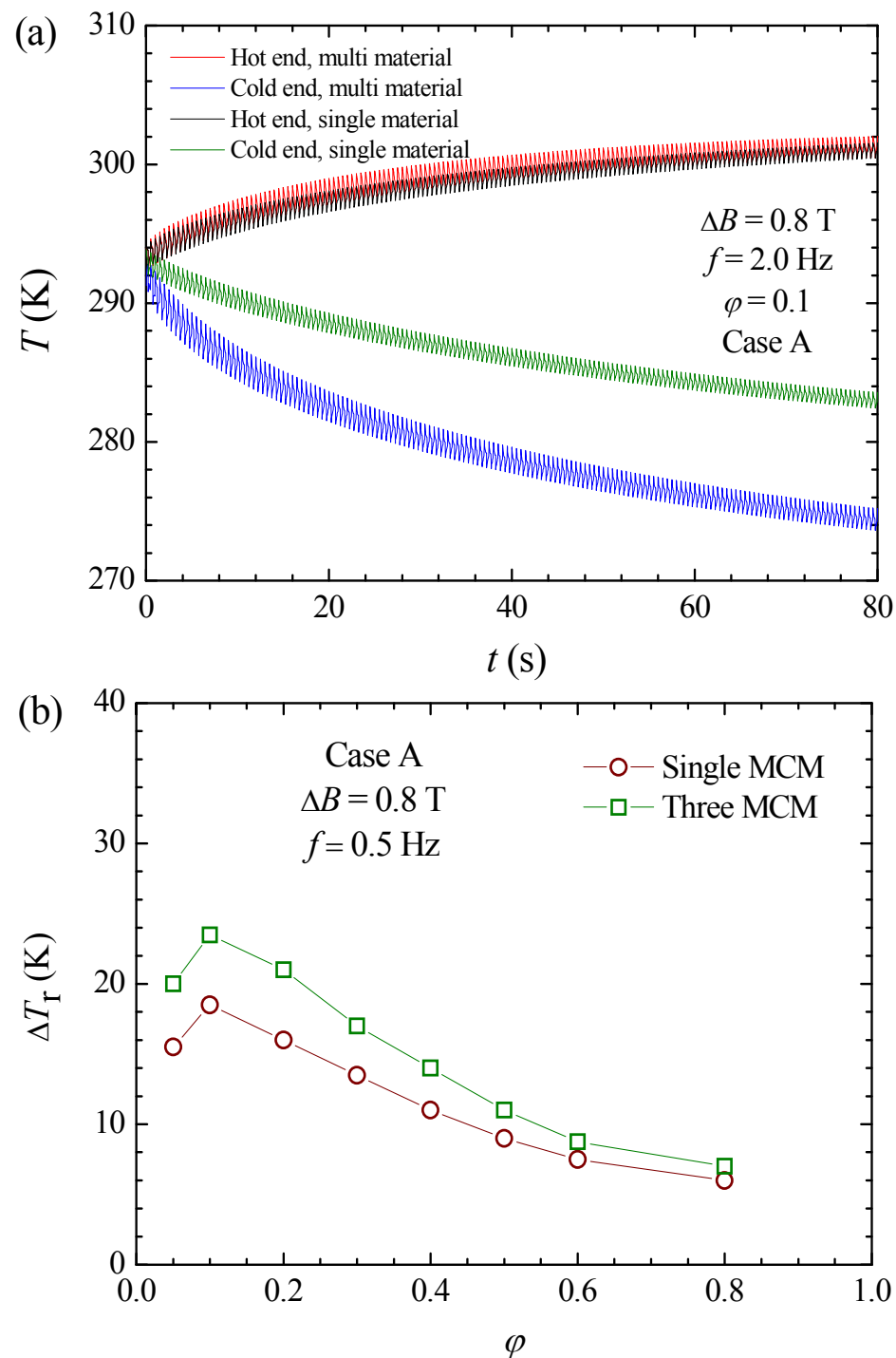

Figure 11 (a) Transient response of single and three-MCM microchannel regenerator for case B (see Table 4) $\Delta B=0.8 \mathrm{~T}, f=0.5 \mathrm{~Hz}$; (b) Variation of no-load temperature span $\Delta T_{\mathrm{r}}$ with utilization for single MCM and three-MCM based regenerators (hypothetical materials).

\subsubsection{Effect of number of MCMs}

Utilization depends upon the specific heat capacity of the MCM as can be seen in Eq. (25). For single-MCM regenerator, the material considered was Gd with known $c_{\mathrm{P}}$ of $290 \mathrm{Jkg}^{-1} \mathrm{~K}^{-1}$ (at $B=0 \mathrm{~T}, T=$ $\left.T_{\mathrm{Cu}}\right)$ and utilization is calculated using this value. However, for the case of multiple MCM, utilization would be determined by the average of heat capacities of different MCMs employed in the regenerator (Nielsen [32]). As MCMs with hypothetical $T_{\mathrm{Cu}}$ have been considered, a simplifying assumption is made and 
utilization is calculated by taking the average heat capacity of different MCMs to be the same as that of Gd. The assumption is reasonable due to minor variation of magnetocaloric properties with change in Curie temperature in the range 280-300 K (email discussion with Dr. Matthias Katter, Vacuumschmelze GmbH). Figure 12 compares the variations of cooling capacity with utilization for single and three-MCM regenerators. For three-MCM microchannel regenerator, two hypothetical MCMs with Curie temperatures of $284 \mathrm{~K}$ and $289 \mathrm{~K}$ are considered with Gd as the third MCM as shown in Figure 5(a). The cooling capacity of three-MCM regenerator is larger than single-MCM and the difference in the corresponding peak values is $\sim 25 \%$.

\section{Single Column Figure}

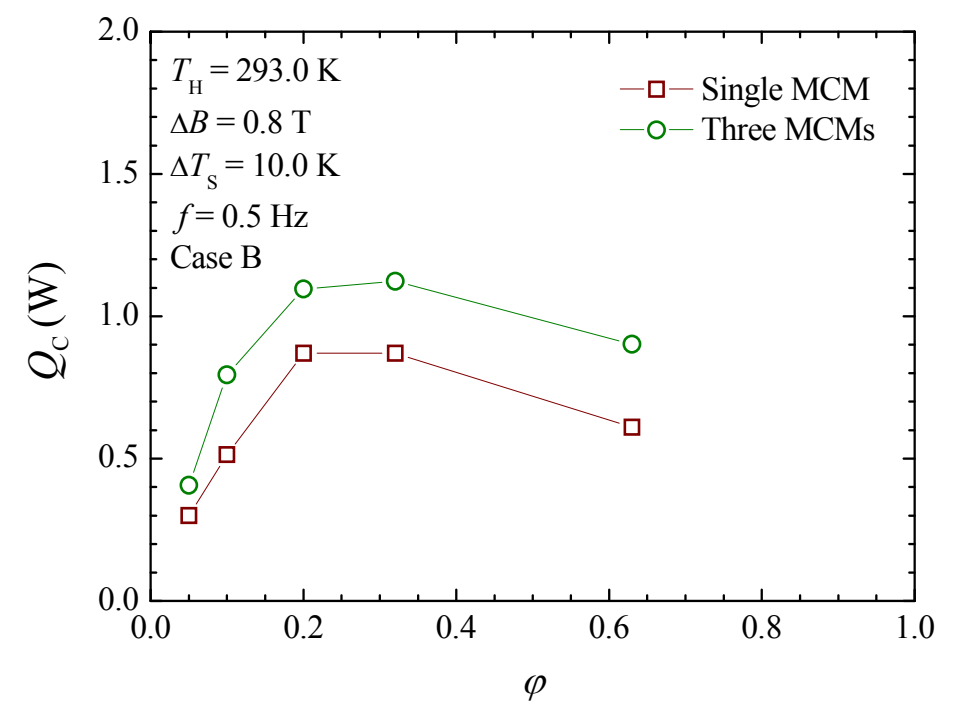

Figure 12 Variation of cooling capacity with utilization for single and three MCM based regenerators for microchannel regenerator Case B (see Table 4), $T_{\mathrm{H}}=293.0 \mathrm{~K} ; \Delta B=0.8 \mathrm{~T}, f=0.5 \mathrm{~Hz}$.

Figure 13(a) shows three cases of microchannel regenerator with different number of MCMs. Single MCM regenerator has $T_{\mathrm{Cu}}=294.0 \mathrm{~K}$. For multi-MCM cases, Curie temperature difference is kept to be $4.0 \mathrm{~K}$ between any two consecutive MCMs. Thus, two-MCM regenerator has $T_{\mathrm{Cu}}$ of $290.0 \mathrm{~K}$ and $294.0 \mathrm{~K}$. For three-MCM case, $T_{\mathrm{Cu}}$ are taken to be $286 \mathrm{~K}, 290 \mathrm{~K}$ and $294 \mathrm{~K}$ while for the four-MCM case $T_{\mathrm{Cu}}$ are $282 \mathrm{~K}$, $286 \mathrm{~K}, 290 \mathrm{~K}$ and $294 \mathrm{~K}$. The three cases are numerically simulated for $1.0 \mathrm{~T}$ change in magnetic field, 0.5 Hz operating cycle frequency and hot end temperature was fixed to $293.0 \mathrm{~K}$.

The variation of cooling capacity with utilization for different number of MMCs is plotted in Figure 13(b). The cooling capacity is found to increase as the number of MCMs is increased for the given cases. For single MCM case, peak cooling capacity is at $\varphi=0.1$, while for two and three MCM cases the peaks are seen 
at $\varphi=0.4$ and are $\sim 13 \%$ and $\sim 28 \%$ higher compared with peak capacity of single MCM regenerator, respectively.

\section{Single Column Figure}

(a) $\quad n_{\mathrm{MCM}}=1$

$$
T_{\mathrm{Cu}}=294.0 \mathrm{~K}
$$

$n_{\mathrm{MCM}}=2$

\begin{tabular}{|l|l|}
\hline$T_{\mathrm{Cu}}=290.0 \mathrm{~K}$ & $T_{\mathrm{Cu}}=294.0 \mathrm{~K}$ \\
\hline
\end{tabular}

$$
n_{\mathrm{MCM}}=3
$$

\begin{tabular}{|l|l|l|}
\hline$T_{\mathrm{Cu}}=286.0 \mathrm{~K}$ & $T_{\mathrm{Cu}}=290.0 \mathrm{~K}$ & $T_{\mathrm{Cu}}=294.0 \mathrm{~K}$ \\
\hline
\end{tabular}

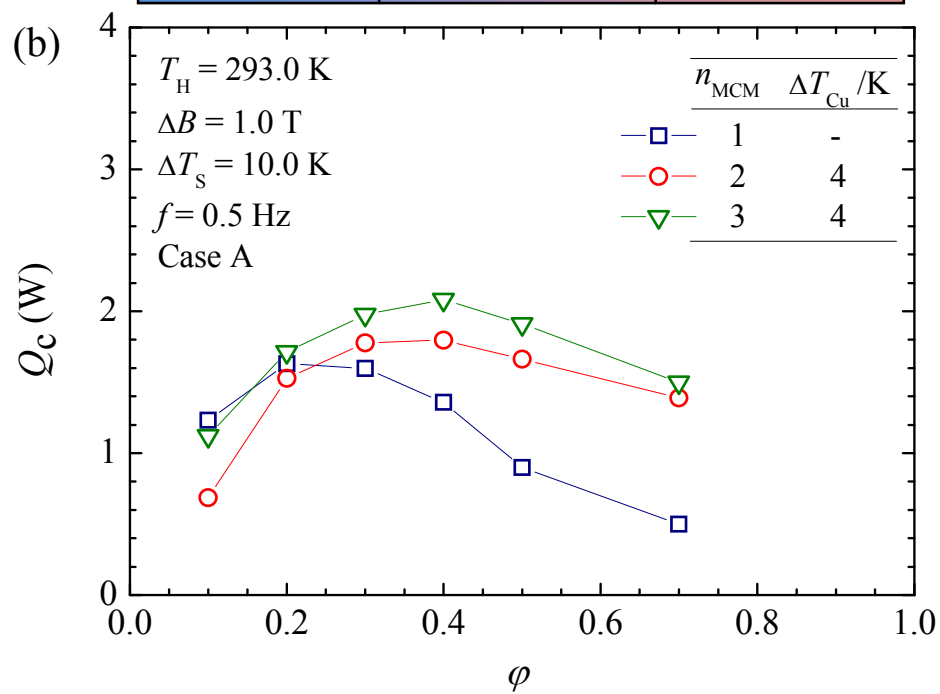

Figure 13 (a) Multi-MCM regenerators with different number of MCMs for $\Delta T_{\mathrm{Cu}}=4 \mathrm{~K}$; (b) Variation of cooling capacity with utilization for no. of MCMs.

\subsubsection{Effect of Curie temperature difference}

The effect of Curie temperature difference $\Delta T_{\mathrm{Cu}}$ between two adjacent MCMs is investigated. Figure 14(a) shows four cases of two-MCM regenerator with different $\Delta T_{\mathrm{Cu}}$ value of $24.0 \mathrm{~K}, 16.0 \mathrm{~K}, 8.0 \mathrm{~K}, 4.0 \mathrm{~K}$ respectively. The MCM at the hotend is assigned $T_{\mathrm{Cu}}=294.0 \mathrm{~K}(\mathrm{Gd})$ in all four cases while $T_{\mathrm{Cu}}$ of the second MCM is different in each case in order to obtain different $\Delta T_{\mathrm{Cu}}$ values.

The cooling capacity curves for different values of $\Delta T_{\mathrm{Cu}}$ are plotted in Figure 14(b). For a given number of MCMs, cooling capacity increases as the $\Delta T_{\mathrm{Cu}}$ decreases. This behaviour is mainly due to the dependence of temperature jump $\Delta T_{\text {ad }}$ (rise and drop) during magnetisation and demagnetisation on the local temperature $T_{\mathrm{s}}$ of the MCM solid (can be seen in Figure 5). To operate at room temperature 293.0 K, the MCM with $T_{\mathrm{Cu}}$ closer to $293.0 \mathrm{~K}$ (in this case Gd with $T_{\mathrm{Cu}}=294.0 \mathrm{~K}$ ) experiences larger temperature change $\Delta T_{\text {ad }}$ while 
MCM with $T_{\mathrm{Cu}}$ farther from $293.0 \mathrm{~K}$ will undergo relatively smaller temperature change. The MCM with $T_{\mathrm{Cu}}$ $=270.0 \mathrm{~K}$ (Figure 5(a)) experiences smaller temperature change during magnetisation/demagnetisation as its local temperature being $293.0 \mathrm{~K}$ and it can be seen from the $\Delta T_{\text {ad }}$ curve of $T_{\mathrm{Cu}}=270 \mathrm{~K}$ in Figure 5(b) the temperature change is $\sim 1 \mathrm{~K}$ at temperature of $293.0 \mathrm{~K}$. However, if $\Delta T_{\mathrm{Cu}}$ is decreased the difference in the temperature of the MCM and its Curie temperature also decreases which results in larger $\mathrm{MCE} / \Delta T_{\text {ad. }}$ The relative larger MCE yields improved performance.

\section{Single Column Figure}

(a) $\Delta T_{\mathrm{Cu}}=24.0 \mathrm{~K}$

\begin{tabular}{|l|l|}
\hline$T_{\mathrm{Cu}}=270.0 \mathrm{~K}$ (hyp) & $T_{\mathrm{Cu}}=294.0(\mathrm{Gd})$ \\
\hline
\end{tabular}

\begin{tabular}{|c|c|}
\hline$\Delta T_{\mathrm{Cu}}=16.0 \mathrm{~K}$ \\
$T_{\mathrm{Cu}}=278.0 \mathrm{~K}$ (hyp) & $T_{\mathrm{Cu}}=294.0(\mathrm{Gd})$ \\
\hline
\end{tabular}

$\Delta T_{\mathrm{Cu}}=8.0 \mathrm{~K}$

\begin{tabular}{|c|c|}
\hline$T_{\mathrm{Cu}}=286.0 \mathrm{~K}$ (hyp) & $T_{\mathrm{Cu}}=294.0(\mathrm{Gd})$ \\
\hline
\end{tabular}

$\Delta T_{r_{n}}=4.0 \mathrm{~K}$

$T_{\mathrm{Cu}}=290.0 \mathrm{~K}$ (hyp) $\quad T_{\mathrm{Cu}}=294.0$ (Gd)

(b)

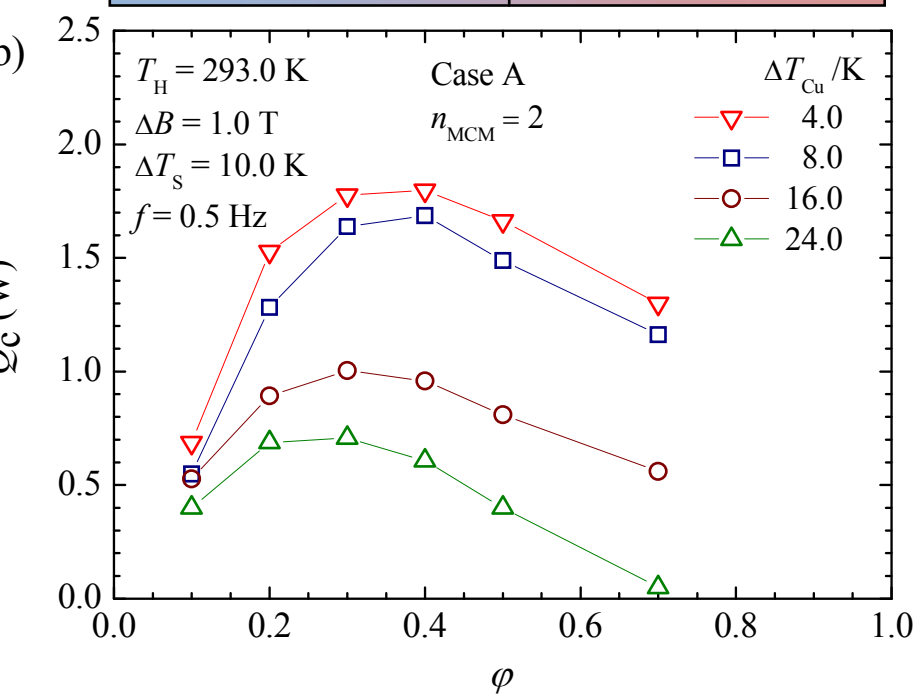

Figure 14 (a) Different cases of $\Delta T_{\mathrm{Cu}}$ for two-MCM regenerator; (b) Variation of $Q_{\mathrm{c}}$ with utilization for different values of $\Delta T_{\mathrm{Cu}}$ for two-MCM regenerator.

\subsubsection{Effect of hot end temperature}

For cooling purpose, the temperature of the hot end is kept constant while temperature at cold end is allowed to drop to be able to absorb heat from cooling load. The cooling capacity is sensitive to the hot side temperature and its influence is investigated by fixing hot end to different temperatures. For two-MCM 
regenerator, the Curie temperatures are taken as $290.0 \mathrm{~K}$ and $294.0 \mathrm{~K}$, and for the case of three MCMs the Curie points are considered to be $286.0 \mathrm{~K}, 290.0$ and $294.0 \mathrm{~K}$ as can be seen in Figure 13(a).

The variation of cooling capacity with the temperature of hot end $T_{\mathrm{H}}$ is shown in Figure 15. For singleMCM regenerator, the peak performance is seen when temperature of the hot end is fixed at $295.0 \mathrm{~K}$ i.e. near the Curie temperature of the employed MCM which is $294.0 \mathrm{~K}$. The cooling capacity drops nearly at the same rate on either side of the cooling capacity peak for $T_{\mathrm{H}}>295.0$ and $T_{\mathrm{H}}<295.0$ for single MCM regenerator.

For two and three-MCM cases the peak performance is still seen around $T_{\mathrm{H}}=295.0 \mathrm{~K}$. However, the drop in the cooling capacity with $T_{\mathrm{H}}$ on either side of the peak follows different trends. For $T_{\mathrm{H}}<295.0 \mathrm{~K}$, the cooling capacity gradient with hot side temperature $\left(\partial Q_{\mathrm{d}} / \partial T_{\mathrm{H}}\right)$ of three-MCM regenerator is much smaller compared with that of the two-MCM regenerator. Also, three-MCM regenerator gives $\sim 50 \%$ higher cooling capacity than single-MCM and $\sim 20 \%$ than two-MCM regenerator at $T_{\mathrm{H}}=285.0 \mathrm{~K}$. The main reason for the improved performance of three-MCM regenerator at $T_{\mathrm{H}}=285.0 \mathrm{~K}$ is the presence of the $\mathrm{MCM}$ with $T_{\mathrm{Cu}}=$ 286.0 K which is, of course, not available in single and two-MCM regenerators. Similarly, the steeper decline of $Q_{\mathrm{c}}$ with $T_{\mathrm{H}}$ of three-MCM regenerator for $T_{\mathrm{H}}>295.0 \mathrm{~K}$ can be reduced by the addition of MCMs with $T_{\mathrm{Cu}}>294.0 \mathrm{~K}$ and the performance can be uplifted for higher $T_{\mathrm{H}}$ (which is advantageous for the ambient temperatures above $300 \mathrm{~K}$ ).

\section{Single Column Figure}

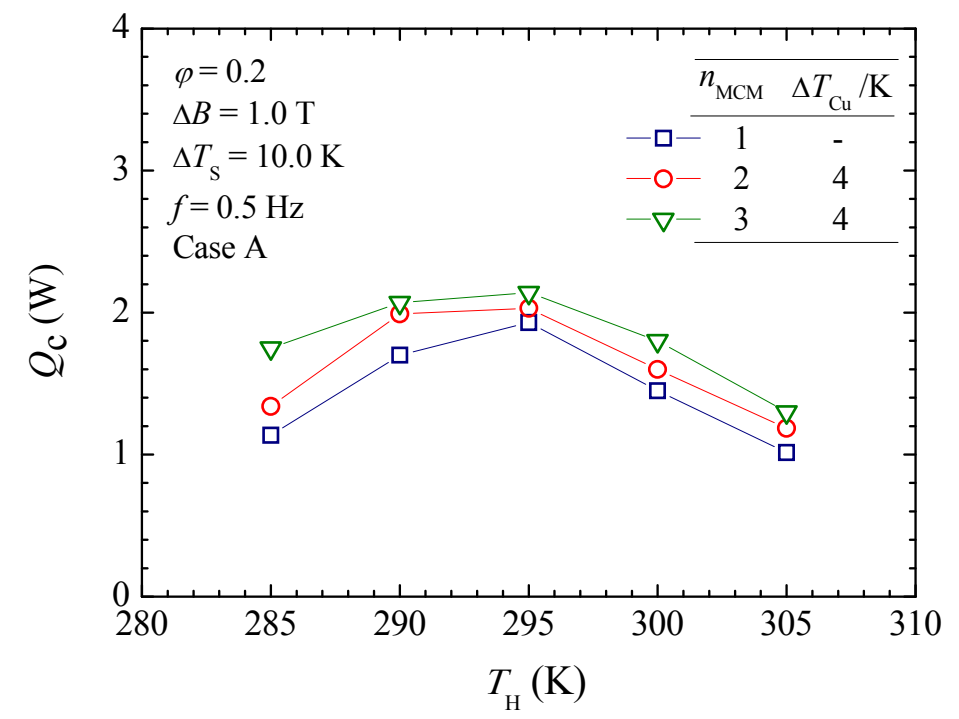

Figure 15 Multi-MCM regenerators with different number of MCMs with $\Delta T_{\mathrm{Cu}}=4 \mathrm{~K}$ between two adjacent MCMs; (b) Variation of cooling capacity with hot side temperature for different number of materials. 


\section{Conclusions}

A hybrid numerical model of a magnetic refrigerator was developed to simulate parallel-plate and microchannel regenerators made of multi-MCMs. The transient thermo-hydraulic response of active magnetic regenerators made of multiple MCMs was simulated using finite volume method based commercial software. The rates of heat transfer at cold and hot end heat exchanger were calculated using $\varepsilon$-NTU method. MCMs were considered with different Curie temperatures both for the commercially available compounds of $\mathrm{LaFe}_{13-\mathrm{x}-\mathrm{y}} \mathrm{Co}_{\mathrm{x}} \mathrm{Si}_{\mathrm{y}}$ and hypothetical compounds of Gd. Discrete method was used for the incorporation of the magnetocaloric effect. Method/model validation was performed with experimental data available in the literature for parallel regenerators made of different compounds of $\mathrm{LaFe}_{13-\mathrm{x}-\mathrm{y}} \mathrm{Co}_{\mathrm{x}} \mathrm{Si}_{\mathrm{y}}$. The model can predict results with a maximum difference of $\sim 15 \%$ from the experimental data. Multi-MCM based regenerator have shown improved performance as compared to single MCM based regenerator. Cooling capacity was seen to increase as the number of MCMs increase, however, for a given length of regenerator there exists an optimum number of materials to obtain the maximum performance. For given number of MCMs, an optimum difference in Curie temperatures of two consecutive MCMs is found to yield improved performance compared with larger $\Delta T_{\mathrm{Cu}}$.

\section{Acknowledgments}

A PhD studentship by University of Engineering and Technology Lahore, Pakistan and EU research grant FP7-2010-IRSES-269205 are gratefully acknowledged. The work was also partly financially supported by the National Natural Science Foundation of China (No. 51176050).

\section{Nomenclature}

A heat transfer area

$a_{\mathrm{p}} \quad$ heat transfer area per unit volume/specific heat transfer area

$B \quad$ intensity of magnetic field

$\Delta B \quad$ maximum change in intensity of magnetic field

C ratio of specific heat capacities 
$c_{P} \quad$ isobaric specific heat capacity

d diameter

$d_{\mathrm{i}} \quad$ inside diameter

$d_{\mathrm{h}} \quad$ hydraulic diameter

$d_{\mathrm{o}} \quad$ outside diameter

$d_{\mathrm{p}} \quad$ cross-sectional diameter of piston

$f \quad$ cycle frequency; rotational frequency; friction factor

$l \quad$ length

L length

$m \quad$ mass; magnetization

$m_{\mathrm{r}} \quad$ mass flow rate in regenerator loop

$n \quad$ number

n vector normal to boundary

$P \quad$ pressure

$q \quad$ heat flux

$Q_{\text {c }}$ heat exchange at CHEX

$Q_{\mathrm{h}} \quad$ heat exchange at HHEX

$R \quad$ radius of crank disk of displacer

$t \quad$ time

$\Delta t \quad$ time step

T temperature

$T_{\mathrm{Cu}} \quad$ Curie temperature

$\Delta T_{\mathrm{r}} \quad$ temperature span between two ends of regenerator

u velocity vector

$u \quad$ velocity in $x$-direction; mean velocity

$U \quad$ overall heat-transfer coefficient

V volume

$v \quad$ velocity in $y$-direction 
$w \quad$ velocity in $\mathrm{z}$-direction

\section{Greek}

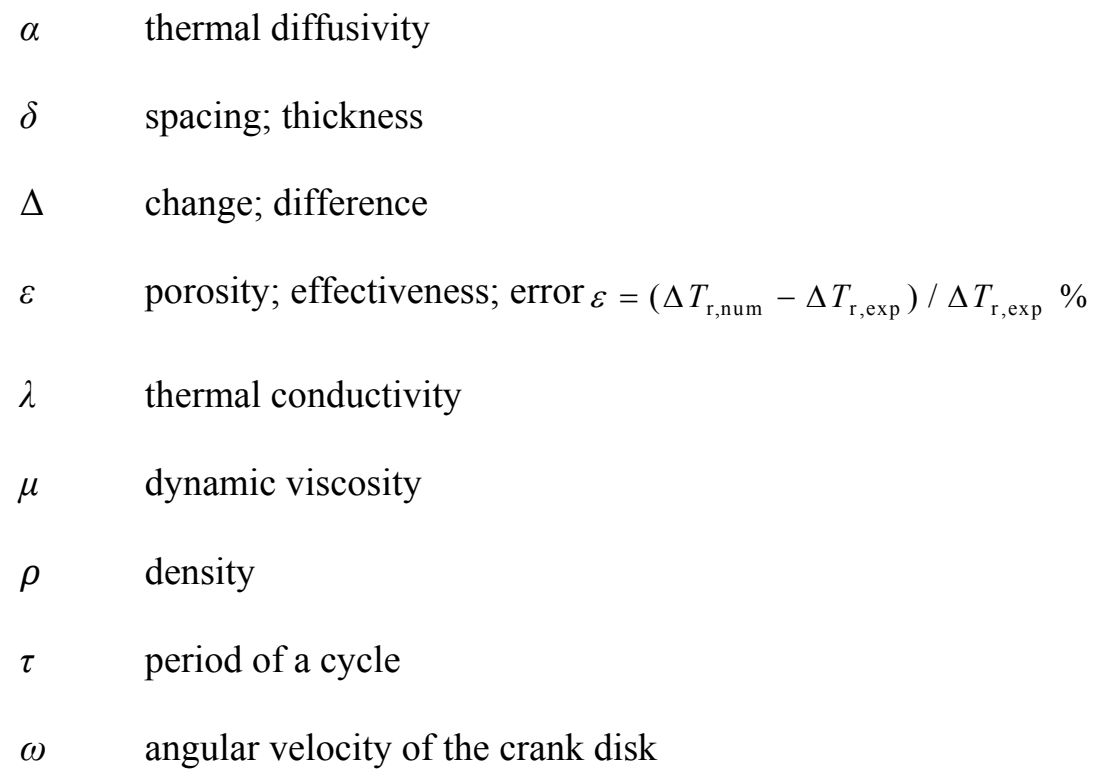

\section{Subscript}

ad adiabatic

b bulk

c cold

cf counter-current flow

ch channel

ele electronic

exp experiment

f fluid

h hot, hydraulic

i inside

init initial

in inlet

j $\quad \mathrm{r}, \mathrm{h}$ or c

lat lattice 


$\begin{array}{ll}\text { mag } & \text { magnetic } \\ \text { min } & \text { maximum } \\ \text { num } & \text { numerical } \\ \text { o } & \text { outside } \\ \text { out } & \text { outlet } \\ \text { pl } & \text { plate } \\ \text { r } & \text { regenerator } \\ \text { s } & \text { solid } \\ \text { tot } & \text { total } \\ \text { w } & \text { wall }\end{array}$

\section{Acronyms}

$\begin{array}{ll}\text { AMR } & \text { active magnetocaloric regenerator } \\ \text { CHEX } & \text { cold and heat exchanger } \\ \text { COP } & \text { coefficient of performance } \\ \text { HHEX } & \text { hot end heat exchanger } \\ \text { MCE } & \text { magnetocaloric effect } \\ \text { MCM } & \text { magnetocaloric material } \\ \text { NTU } & \text { number of transferred units } \\ \text { UDF } & \text { user-defined function }\end{array}$

\section{References}

[1]. Morrish, A., The Physical Principles of Magnetism, 1965: John Wiley \& Sons Inc.

[2]. Tishin, A. M. and Spichkin, Y. I., The Magnetocaloric Effect and its Applications, 2003: Institute of Physics Publishing.

[3]. Pecharsky, V. K. and Gschneidner, K. A., Giant Magnetocaloric effect in Gd5(Si2Ge2), Physical Review Letters, 78(1997).

[4]. Dan'kov, S. Y., Tishin, A. M., Pecharsky, V. K. and Gschneidner Jr., K. A., Magnetic phase transitions and the magnetothermal properties of gadolinium, Physical Review B, 57(1998): p. 34783490. 
[5]. Yu, B. F., Liu, M., Egolf, W. and Kitanovski, A., A review of magnetic refrigerator and heat pump prototypes built before the year 2010, International Journal of Refrigeration, 36(2010): p. 10291060.

[6]. Scarpa, F., Tagliafico, G. and Tagliafico, L. A., A classification methodology applied to existing room temperature magnetic refrigerators up to the year 2014, Renewable and Sustainable Energy Reviews, 50(2015): p. 497-503.

[7]. Diguet, G., Lin, G. and Chen, J., Effect of geometrical shape of the working substance Gadolinium on the performance of a regenerative magnetic Brayton refrigeration cycle, Journal of Magnetism and Magnetic Materials, 326(2013): p. 103-107.

[8]. Bjørk, R., Bahl, C. R. H., Smith, A. and Pryds, N., Review and comparison of magnet designs for magnetic refrigeration, International Journal of Refrigeration, 33(2010): p. 437-448.

[9]. Arnold, D. S., Tura, A. and Rowe, A., Experimental analysis of a two-material active magnetic regenerator, International Journal of Refrigeration, 34(2011): p. 178-191.

[10]. Tusek, J., Kitanovski, A., Tomc, U., Favero, C. and Poredos, A., Experimental comparison of multilayered $\mathrm{LaFeCoSi}$ and single-layered $\mathrm{Gd}$ active magnetic regenerators for use in a room temperature magnetic refrigerator, International Journal of Refrigeration, 37(2014): p. 117-126.

[11]. Legait, U., Guillou, F., Kedous-Lebouc, A., Hardy, V. and Almanza, M., An experimental comparison of four magnetocaloric regenerators using three different materials, International Journal of Refrigeration, 37(2014): p. 147-155.

[12]. Aprea, C., Greco, A. and Maiorino, A., A numerical analysis of an active magnetic regenerative refrigerant system with a multi-layer regenerator, Energy Conversion and Management, 52(2011): p. 97-107.

[13]. Hsieh, C. M., Su, Y. C., Lee, C. H., Cheng, P. H. and Leou, K. C., Modeling of Graded Active Magnetic Regenerator for Room-Temperature, Energy-Efficient Refrigeration, Magnetics, IEEE Transactions on, 50(2014): p. 1-4.

[14]. Monfared, B. and Palm, B., Optimization of layered regenerator of a magnetic refrigeration device, International Journal of Refrigeration, 57(2015): p. 103-111.

[15]. Lei, T., Nielsen, K. K., Engelbrecht, K., Bahl, C. R. H., Neves Bez, H. and Veje, C. T., Sensitivity study of multi-layer active magnetic regenerators using first order magnetocaloric material $\mathrm{La}(\mathrm{Fe}, \mathrm{Mn}, \mathrm{Si}) 13 \mathrm{Hy}$, Journal of Applied Physics, 118(2015): p. 014903.

[16]. Chiba, Y., Sari, O., Smaïli, A., Mahmed, C. and Nikkola, P., Experimental Study of a Multilayer Active Magnetic Regenerator Refrigerator-Demonstrator, in Progress in Clean Energy, Volume 1, I. Dincer, et al., Editors. 2015, Springer International Publishing. p. 225-233.

[17]. Katter, M., Zellmann, V., Reppel, G. W. and Uestuener, K., Magnetocaloric properties of La(Fe, Co, Si)13 bulk material prepared by power metallurgy, IEEE Transactions on Magnetics, 44(2008): p. 3044-3047.

[18]. Katter, M., Zellmann, V., Reppel, G. W. and Uestuener, K., Magnetocaloric and mechanical properties of reactively sintered $\mathrm{La}(\mathrm{Fe}, \mathrm{Co}, \mathrm{Si}) 13$, In proc: 3rd IIF-IIR International Conference on Magnetic Refrigeration at Room Temperature, Thermag III, 2009, Des Moines, Iowa, USA.

[19]. Katter, M., Zellmann, V. and Barcza, A., Sintering behaviour and thermally induced decomposition and recombination (TDR) process of LaFe13_x_yCoxSiy alloys, In proc: 4th International Conference on Magnetic Refrigeration at Room Temperature, International Institute of Refrigeration, 2010, Batou, Inner Mongolia, China.

[20]. Bjørk, R., Bahl, C. R. H. and Katter, M., Magnetocaloric properties of LaFe13-x-yCoxSiy and commercial grade Gd, Journal of Magnetism and Magnetic Materials, 322(2010): p. 3882-3888.

[21]. Barcza, A., Katter, M., Zellmann, V., Russek, S., Jacobs, S. and Zimm, C., Stability and magnetocaloric properties of sintered $\mathrm{La}(\mathrm{Fe}, \mathrm{Mn}, \mathrm{Si}) 13 \mathrm{~Hz}$ alloys, IEEE Transactions on Magnetics, 47(2011): p. 3391-3394.

[22]. Bahl, C. R. H., Bjørk, R., Smith, A. and Nielsen, K. K., Properties of magnetocaloric materials with a distribution of Curie temperatures, Journal of Magnetism and Magnetic Materials, 324(2012): p. 564-568.

[23]. Radulov, I. A., Skokov, K. P., Karpenkov, D. Y., Gottschall, T. and Gutfleisch, O., On the preparation of $\mathrm{La}(\mathrm{Fe}, \mathrm{Mn}, \mathrm{Si}) 13 \mathrm{Hx}$ polymer-composites with optimized magnetocaloric properties, Journal of Magnetism and Magnetic Materials, 396(2015): p. 228-236.

[24]. Pulko, B., Tušek, J., Moore, J. D., Weise, B., Skokov, K., Mityashkin, O., Kitanovski, A., Favero, C., Fajfar, P., Gutfleisch, O., Waske, A. and Poredoš, A., Epoxy-bonded La-Fe-Co-Si magnetocaloric plates, Journal of Magnetism and Magnetic Materials, 375(2015): p. 65-73. 
[25]. Nielsen, K. K., Tusek, J., Engelbrecht, K., Schopfer, S., Kitanovski, A., Bahl, C. R. H., Smith, A., Pryds, N. and Poredos, A., Review on numerical modeling of active magnetic regenerators for room temperature applications, International Journal of Refrigeration, 34(2011): p. 603-616.

[26]. Engelbrecht, K., A Numerical Model of an Active Magnetic Regenerator Refrigerator with Experimental Validation, 2008, University of Wisconsin, Madison.

[27]. Cengel, Y. A., Heat Transfer: a Practical Approach, 2nd ed, 2003: McGraw-Hill.

[28]. Gnielinski, V., New equations for heat and mass transfer in turbulent pipe and channel flow, Int. Chemical Engineering, 16(1976): p. 359-368.

[29]. Filonenko, G. K., Hydraulic Resistance in Pipes, Teploergetica, 1(1954): p. 40-44.

[30]. Nielsen, K. K., Bahl, C. R. H., Smith, A., Bjork, R., Pryds, N. and Hattel, J., Detailed numerical modeling of a linear parallel-plate Active Magnetic Regenerator, International Journal of Refrigeration, 32(2009): p. 1478-1486.

[31]. Holman, J. P., Heat Transfer, 1986: McGraw-Hill Education.

[32]. Nielsen, K. K., Numerical modeling and analysis of the active magnetic regenerator, 2010, DTU, Denmark. 